\title{
Structure of the North Anatolian Fault Zone imaged via teleseismic scattering tomography
}

\author{
S. Rost ${ }^{1}$ (s.rost@leeds.ac.uk) \\ G. Houseman ${ }^{1}$ (G.A.Houseman@leeds.ac.uk) \\ A. W. Frederiksen² (Andrew.Frederiksen@umanitoba.ca) \\ D. G. Cornwell ${ }^{3}$ (d.cornwell@abdn.ac.uk) \\ M. Kahraman ${ }^{4}$ (metin.kahraman@boun.edu.tr) \\ S. Altuncu Poyraz ${ }^{4}$ (selda.altuncu@boun.edu.tr) \\ U.M. Teoman ${ }^{4}$ (ugurt@boun.edu.tr)

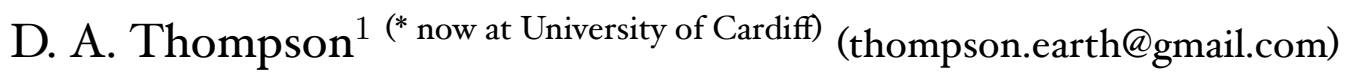 \\ N. Türkellii (turkelli@boun.edu.tr) \\ L. Gülen ${ }^{5}$ (lgulen@sakarya.edu.tr) \\ M. Utkucu ${ }^{5}$ (mutkucu@sakarya.edu.tr) \\ T.J. Wright ${ }^{6}$ (T.J.Wright@leeds.ac.uk)
}

\footnotetext{
${ }^{1}$ School of Earth and Environment, The University of Leeds, Leeds, LS $29 f T$,

${ }^{2}$ Department of Geological Sciences, University of Manitoba, Winnipeg, Manitoba, Canada,

${ }^{3}$ Department of Geology and Geophysics, School of Geosciences, University of Aberdeen, King's College, Aberdeen, $\mathrm{AB}_{2} 4{ }_{3} \mathrm{UE}$, United Kingdom,

${ }^{4}$ Kandilli Observatory and Earthquake Research Institute, Department of Geophysics, Boğaçizi University, 34684 Cengelköy, Istanbul, Turkey,

${ }^{5}$ Department of Geophysical Engineering, Sakarya University, Esentepe Campus, 54I87, Sakarya, Turkey

${ }^{6}$ COMET, School of Earth and Environment, The University of Leeds, Leeds, LS2 $9 \mathcal{F} T$
}

This manuscript has been submitted for publication in Geophysical Journal International and is undergoing peer-review. Please note that the manuscript has not been formally accepted for publication. Subsequent versions of this manuscript may have slightly different content. If accepted, the final version of this manuscript will be available via the Peer-review Publication DOI link on this webpage. Please feel free to contact the authors; We welcome feedback. 
Structure of the North Anatolian Fault Zone imaged via teleseismic scattering tomography
S. Rost $^{1}$
G. Houseman ${ }^{1}$
A. W. Frederiksen ${ }^{2}$
D. G. Cornwell ${ }^{3}$
M. Kahraman ${ }^{4}$
S. Altuncu Poyraz ${ }^{4}$
U.M. Teoman ${ }^{4}$
D. A. Thompson ${ }^{1 \star}$
N. Türkellii ${ }^{4}$
L. Gülen ${ }^{5}$
M. Utkucu ${ }^{5}$ 


\section{T.J. Wright ${ }^{6}$}

${ }^{1}$ School of Earth and Environment, The University of Leeds, Leeds, LS2 9JT,

2 Department of Geological Sciences, University of Manitoba, Winnipeg, Manitoba, Canada,

${ }^{3}$ Department of Geology and Geophysics, School of Geosciences, University of Aberdeen, King's College, Aberdeen, A

${ }^{4}$ Kandilli Observatory and Earthquake Research Institute, Department of Geophysics, Boğaçizi University, 34684 Ceng

${ }^{5}$ Department of Geophysical Engineering, Sakarya University, Esentepe Campus, 54187, Sakarya, Turkey

${ }^{6}$ COMET, School of Earth and Environment, The University of Leeds, Leeds, LS2 9JT

Received ...; in original form ...

\section{SUMMARY}

Information on fault zone structure is essential for our understanding of earthquake mechanics, continental deformation and our understanding of seismic hazard. We use the scattered seismic wavefield to study the subsurface structure of the North-Anatolian Fault Zone (NAFZ) in the region of the 1999 İzmit and Düzce rupture using data from an 18-month dense deployment of seismometers with a nominal station spacing of $7 \mathrm{~km}$. Using the forward and backscattered energy following the direct $P$-wave arrival from teleseismic earthquakes, we apply a scattered wave inversion approach and are able to resolve fine-scale changes in lithospheric structure on scales of $10 \mathrm{~km}$ or less in an area of about $130 \mathrm{~km}$ by $100 \mathrm{~km}$ across the NAFZ. We find several crustal interfaces that are laterally incoherent beneath the surface strands of the NAFZ and evidence for contrasting crustal structures either side of the NAFZ, consistent with the presence of juxtaposed crustal blocks and ancient suture zones. Although the two strands of the NAFZ in the study region strike roughly east-west, we detect strong variations in structure both northsouth, across boundaries of the major blocks, and east-west, parallel to the strike of the NAFZ. The shallow NAFZ is coincident with features detected on the crust-mantle boundary (Moho) and deeper into the mantle. We show that a dense passive network of seismometers is able to capture information from the scattered seismic wavefield and using a tomographic approach, resolving the fine scale structure of crust and lithospheric mantle even in geologically complex 
regions. Our results show that major shear zones exist as narrow structures beneath the NAFZ throughout the crust and into the lithospheric mantle, suggesting a strong coupling of strain across these depths.

Key words: Seismology, Teleseismic Scattering, Tomography, North Anatolian Fault Zone.

\section{INTRODUCTION}

2 The North Anatolian Fault Zone (NAFZ) is one of the longest continuous continental strike slip

3 fault systems on Earth. The NAFZ is a $1500 \mathrm{~km}$ long, right-lateral strike slip fault running the 4 length of northern Anatolia, separating the Eurasian plate to the north from the deforming Anato5 lian region in the south accommodating the relative motion and deformation between these tectonic 6 domains. Together with the East Anatolian Fault, the NAFZ accommodates the westward motion of Anatolia (McKenzie, 1972; Reilinger et al., 2006; Şengör et al., 2005; Barka, 1992) driven by kinematic extrusion of a rigid Anatolian block, or by the gradient of gravitational potential energy from the Anatolian plateau to the Hellenic Trench (England et al., 2016).

While the deformation at the surface is localized on faults (Hussain et al., 2016; Bürgmann \& Dresen, 2008), the distribution of deformation throughout the crust and into the mantle remains unclear (Bürgmann \& Dresen, 2008; Vauchez et al., 2012; Moore \& Parsons, 2015). The structure and dynamics of fault zones such as the NAFZ are essential for our understanding of continental deformation and seismic hazard.

The NAFZ ruptured in a series of $M \geqq 6.7$ earthquakes during the 20th century from east to west (Stein et al., 1997) interpreted as stress transfer along the strike of the NAFZ from one earthquake bringing the next segment closer to failure. The two most recent events in the current series occurred in 1999 with epicentres in İzmit $(M=7.6)$ and Düzce (M=7.2) (Barka et al., 2002; Gülen, 2002) with the fault rupture extending into the Sea of Marmara and the next anticipated event in the series posing a pronounced risk to the city of Istanbul.

To better understand the structure of the NAFZ, especially in the middle and lower crust and

* now at University of Cardiff 
into the upper mantle, we exploit the scattered seismic wavefield following the $P$-wave arrivals ${ }_{23}$ of teleseismic events (Frederiksen \& Revenaugh, 2004), allowing us to resolve the fine scale

structure of the lithosphere in the study region using data from the 18-month DANA deployment (DANA, 2012) deployed across the NAFZ in the region of the 1999 ruptures (Fig. 1a). The $P$-wave coda contains energy from $P$-to- $P$ and $P$-to- $S$ scattering at small-scale heterogeneities along the ray-paths. Structure can be recovered from the scattered seismic energy through migration approaches ranging from common-conversion-point or common-scattering-point stacking (e.g. Dueker \& Sheehan, 1997) to full depth migration (e.g. Ryberg \& Weber, 2000). Here we are using a tomographic waveform approach based on linear inverse theory of the scattered wavefield (Ji \& Nataf, 1998; Frederiksen \& Revenaugh, 2004).

We find that the two strands of the NAFZ evident in the shallow structure coincide with main interfaces and interface terminations throughout the crust and into the upper mantle indicating that the fault zone structure may extend to depths of at least $\sim 75 \mathrm{~km}$ in this region. We find evidence for small-scale variation of structure in the vicinity of the strands that might indicate the detection of heterogeneity related to past deformation along the present day fault.

\section{TECTONICS AND PREVIOUS GEOPHYSICAL SURVEYS}

The study region (Fig. 1b) is an amalgam of continental and subduction-related oceanic fragments that remain after the closing of the Tethyan Ocean in the late Tertiary (e.g. Okay et al., 2008; Robertson \& Ustaömer, 2004) and the NAFZ diverges into a northern and southern strand west of about $30.65^{\circ} \mathrm{E}$. There are three main tectonic blocks sampled by the DANA network: (i) The Istanbul-Zonguldak Zone (IZ) to the north of the northern strand of the NAFZ, (ii) the Sakarya zone (SZ) to the south of the southern strand and (iii) the Armutlu and Almackk blocks (AA) between the two strands. The northern (NNAFZ) and southern strands (SNAFZ) in the study region run roughly along the Armutlu-Istanbul and Sakarya-Armutlu block boundaries, respectively (Emre et al., 2018). Slip on the northern and southern NAFZ strands has been estimated to be approximately 16-25 mm/yr and 5-19 mm/yr, respectively (Stein et al., 1997; Flerit et al., 2003; Meade et al., 2002). The northern branch of the NAFZ ruptured in the 1999 İzmit earthquake (Tibi 

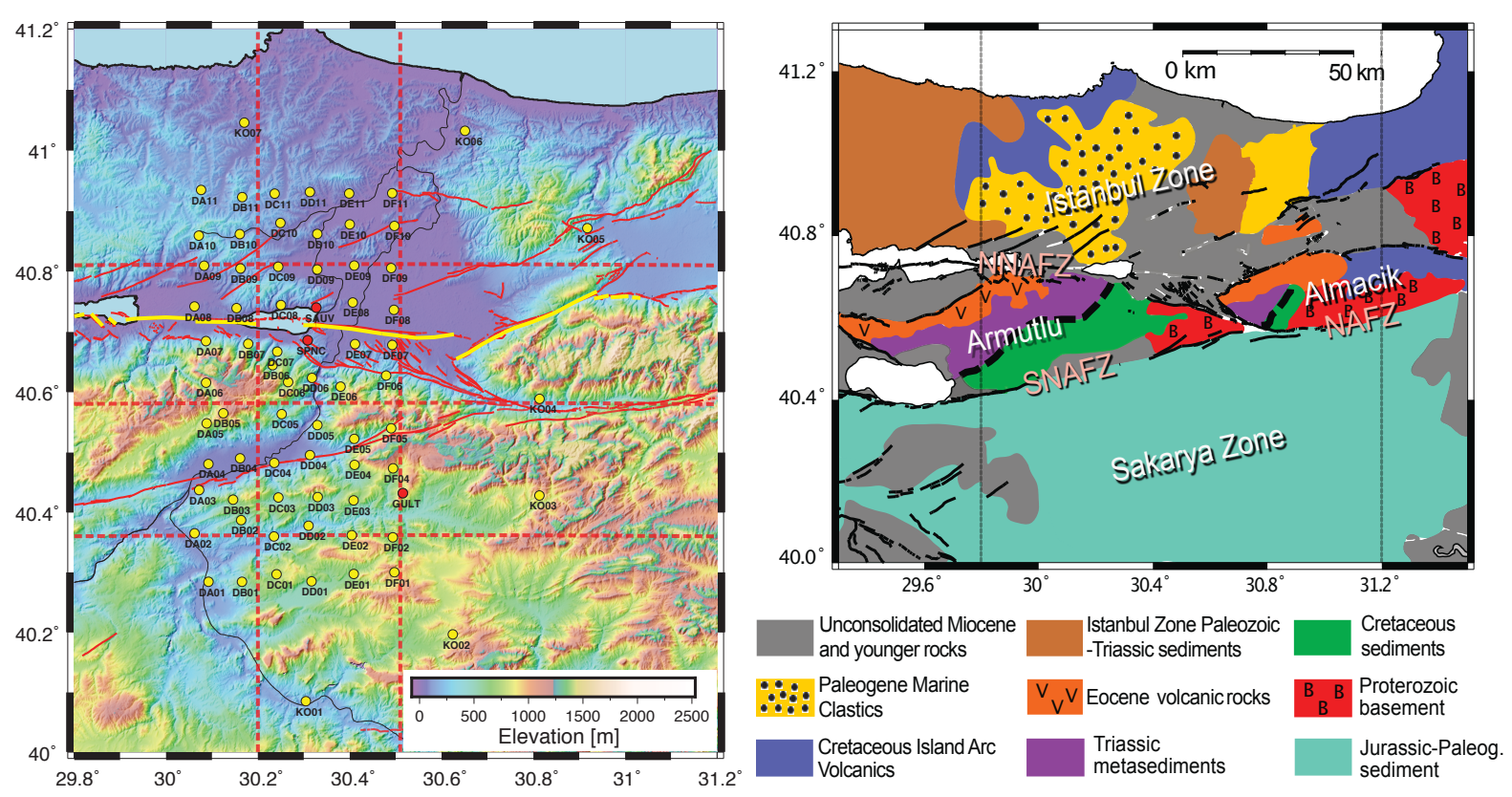

Figure 1. Study region. (a) Topographical map of the study region using SRTM data (Farr et al., 2007). Stations are indicated by yellow circles (permanent stations in red). Mapped faults (red lines) provided by Emre et al. (2018) and rupture of the 1999 Izmit and Dücze earthquakes (yellow) provided by Gülen (2002). Dashed north-south and east-west lines indicate location of depth profiles shown in Fig. 6 and 7 and are approximate locations of depth profiles provided by Kahraman et al. (2015). (b) Geological map of the region outlining the three main tectonic blocks and geological areas. After Taylor et al. (2019).

et al., 2001; Barka et al., 2002) and still shows active slip at the surface (Hussain et al., 2016) although current seismicity is not focussing beneath either fault strand (Altuncu Poyraz et al., ${ }_{51}$ 2015). In general, the NAFZ seems to follow the Intra-Pontide Suture (IPS) between the Istanbul ${ }_{52}$ and Sakarya Zone (e.g. Okay et al., 2008) with the complication of the Almacik and Armutlu blocks lying between these two continental fragments in the study area, with a distinctly different ${ }_{54}$ near-surface velocity structure (Taylor et al., 2019). The structure of the Almackk and Armutlu blocks are potentially the cause for the splay (e.g. Akbayram et al., 2016).

The study region has been sampled by two seismic refraction experiments crossing all major (Bekler \& Gürbüz, 2008) and $\approx 38 \mathrm{~km}$ at about $29.25^{\circ}$ longitude in the west of our study region (Karahan et al., 2001). The refraction data show evidence for a $5 \mathrm{~km}$ thick upper crustal layer with $P$-wave velocities $\left(V_{P}\right)$ of 5.6 to $6.1 \mathrm{~km} / \mathrm{s}$ and lower crustal velocities of $V_{P}=6.7-7.2$ 
$\mathrm{km} / \mathrm{s}$ (Bekler \& Gürbüz, 2008). The upper mantle between $29.5^{\circ}$ and $30.0^{\circ} \mathrm{E}$ is relatively slow $\left(V_{P}=7.6 \mathrm{~km} / \mathrm{s}\right)($ Bekler \& Gürbüz, 2008), while Karahan et al. (2001) find higher mantle velocities further east $\left(29.0^{\circ}\right.$ to $\left.29.5^{\circ} \mathrm{E}\right)$ with velocities of $V_{P} \approx 8.1 \mathrm{~km} / \mathrm{s}$. There is evidence for seismic discontinuities at crustal depths of $\sim 17 \mathrm{~km}$ and $\sim 24 \mathrm{~km}$ (Karahan et al., 2001).

A study using local earthquake waveforms (Horasan et al., 2002) finds a Moho depth at $32 \mathrm{~km}$ in the Marmara region. They find crustal discontinuities at $4 \mathrm{~km}$ and $17 \mathrm{~km}$ depth with upper mantle velocities of $8.00 \mathrm{~km} / \mathrm{s}$ and $4.6 \mathrm{~km} / \mathrm{s}$ for $V_{P}$ and $V_{S}$, respectively and mantle densities of $3.35 \mathrm{~g} / \mathrm{cm}^{3}$. Upper crustal velocities are found to be $5.8 \mathrm{~km} / \mathrm{s}$ and $3.4 \mathrm{~km} / \mathrm{s}$ for $V_{P}$ and $V_{S}$, lower crustal velocities of $6.2 \mathrm{~km} / \mathrm{s}$ and $3.6 \mathrm{~km} / \mathrm{s}$ and near-surface velocities of $3.5 \mathrm{~km} / \mathrm{s}$ and $2.2 \mathrm{~km} / \mathrm{s}$ (Horasan et al., 2002).

$P$-wave receiver functions (PRFs) east of the Marmara sea indicate a deepening of the Moho from west (29 to $32 \mathrm{~km}$ ) to east (34 to $35 \mathrm{~km}$ ) (Zor et al., 2003; Vanacore et al., 2013). The average crustal $V_{P} / V_{S}$ in our study region is $\sim 1.75$ (Vanacore et al., 2013). PRFs of the DANA dataset (Kahraman et al., 2015) find crustal thickness and $V_{P} / V_{S}$ variation in both EW and NS directions with the crust deepening from $36.5 \mathrm{~km}\left(V_{P} / V_{S}=1.73\right)$ to $40 \mathrm{~km}\left(V_{P} / V_{S}=1.73\right)$ in the IZ, a constant crustal thickness of $\sim 37 \mathrm{~km}\left(V_{P} / V_{S}=1.69\right.$ to 1.70$)$ in the AA, and a slight thinning from $\sim 35 \mathrm{~km}\left(V_{P} / V_{S}=1.73\right)$ in the west to $\sim 34 \mathrm{~km}\left(V_{P} / V_{S}=1.85\right)$ in the east of the SZ (Fig. 1). Combining data from several permanent stations and temporary station deployments, including DANA data, Jenkins et al. (2020) determined Moho depths across the Sea of Marmara region finding thick crust of up to $41 \mathrm{~km}$ in the IZ, with a shallower Moho $(32-34 \mathrm{~km})$ in the AA and SZ with a sharp step in Moho depth across the NNAFZ. The transition also shows complex Moho structure around the NNAFZ. Additionally, Jenkins et al. (2020) find east-west variation with a general deepening of the Moho towards the east.

There is evidence in previous studies for strong crustal heterogeneity on scales of less than $10 \mathrm{~km}$ with sharp truncations of sub-horizontal interfaces coinciding with the surface locations of the northern and southern NAFZ strands. The northern strand seems to penetrate deeper into the crust and may extend into the upper mantle (Kahraman et al., 2015). Similar Moho structure has also been imaged using ambient noise auto-correlations (Taylor et al., 2016). 
Using $P$-wave transfer functions and a grid-search inversion approach Frederiksen et al. (2015) detected a sharp change of crustal thickness across the northern NAFZ which is believed to follow the trace of the Intra-Pontide suture in this location and a change of the $V_{P} / V_{S}$ ratio across the southern branch indicating a change in basement composition. The IZ shows thick crust but low topography indicating that it is in isostatic disequilibrium or underlain by thicker lithosphere, a result supported by Jenkins et al. (2020). The transfer functions also provide evidence for thick sediments in Sakarya and Pamukova basins in agreement with ambient noise analysis (Taylor et al., 2019).

Teleseismic $P$-wave and $S$-wave tomography using the DANA dataset (Papaleo et al., 2017, 2018) shows narrow low-velocity zones originating at the surface trace of both strands of the NAFZ and extending throughout the crust. These low velocities were interpreted as zones of localised shear related to the active faults which likely extend into the upper mantle, although it appears to widen with depth as lateral resolution decreases (Papaleo et al., 2017, 2018).

Magnetotelluric (MT) data show differences in the crustal conductivity from south to north across the NAFZ (Tank et al., 2005) with a high resistivity $(\geq 1000 \Omega \mathrm{m})$ crustal basement in the IZ to the north and a less resistive crustal basement $(500 \Omega \mathrm{m})$ in the SZ. The MT data resolve a narrow conductive zone ( 30 to $50 \Omega \mathrm{m}$ ) within the AA that extends into the upper mantle that has been attributed to partial melts or pore fluid flow from the upper mantle beneath the NAFZ.

\section{METHOD}

We apply the teleseismic scattering tomography approach by Frederiksen \& Revenaugh (2004) to the DANA dataset to resolve the small-scale structure beneath the array. The scattered seismic wavefield is more sensitive to short-wavelength variations in material properties than is the path-integrated sensitivity of transmitted phases such as used in e.g. seismic traveltime tomography. The $P$-to- $p$ and $P$-to-s scattered energy in the coda of teleseismic $P$-waves travelling along different paths to the main arrival can uniquely determine Earth structure if the sampling of the seismic wavefield is dense enough to avoid spatial aliasing. In the tomographic approach some aliasing can be accepted without introducing issues with non-uniqueness of the solution due to 
the regularization of the problem. Several approaches to use the scattered coda energy to image the subsurface have been developed, forming a continuous spectrum of method complexity. The common approach of receiver function analysis uses stacked records of $P$-to-s (or $S$-to- $p$ ) scattered (converted) energy (Vinnik, 1977; Langston, 1979) which may be binned according to their common conversion point to improve signal-to-noise ratio (Dueker \& Sheehan, 1997) and mapped to depth. The method assumes a 1D stratified seismic structure which is often violated in practice (Rondenay, 2009). Lateral variation of structure leads to diffraction of the seismic wavefield and diffraction stacking, a backprojection of the diffracted energy along its traveltime hyperbola, can be used to image small-scale perturbations of the structure at depth. These methods are widely used in controlled-source type applications (Yilmaz, 2001), and are commonly described as migration techniques (Rondenay, 2009) but implementation requires dense spatial sampling of the seismic wavefield. General improvements and densification of recent passive seismic deployments make the application of more complex methods, such as traveltime stacking of the scattered wavefield (Revenaugh, 1995) or the application of inversion or backprojection operators in a 2D or 3D model space (Bostock \& Rondenay, 1999) possible and allow higher resolution of detail. For a full review of these methods see Rondenay (2009).

For a more complete treatment of the scattering problem, the scattering image problem can be formulated as a tomographic inversion (Ji \& Nataf, 1998). Using a waveform inversion, Frederiksen \& Revenaugh (2004) have developed a linear tomographic inversion of the scattered seismic wavefield which we apply here. A full description is given in Frederiksen \& Revenaugh (2004) and we outline only the main points of this approach here.

In the standard derivation of seismic scattering in the Born approximation, assuming single scattering, the scattering properties are represented as perturbations in elastic parameters $(\delta \lambda, \delta \mu$, $\delta \rho)$ to a background model $\left(\lambda_{0}, \mu_{0}, \rho_{0}\right)$. The seismic equation of motion in an isotropic medium is given by:

$$
\rho \ddot{u}_{i}=(\lambda \nabla \cdot \mathbf{u})_{, i}+\left[\mu\left(u_{i, j}+u_{j, i}\right)\right]_{, j}
$$


which can be expanded, using small perturbations to the elastic properties $(\delta \lambda, \delta \mu, \delta \rho)$ (Frederiksen \& Revenaugh, 2004), to:

$$
\begin{aligned}
\rho_{0} \ddot{u}_{i}- & \left(\lambda_{0}+\mu_{0}\right)(\nabla \cdot \mathbf{u})_{, i}= \\
& -\delta \rho \ddot{u}_{i}+(\delta \lambda+\delta \mu)(\nabla \cdot \mathbf{u})_{, i}+\delta \mu \nabla^{2} u_{i} \\
& +(\delta \lambda)_{, i}(\nabla \cdot \mathbf{u})+(\delta \mu)_{, j}\left(u_{i, j}+u_{j, i}\right)
\end{aligned}
$$

The wavefield can then be divided into a primary (background) and scattered component $(\mathbf{u}=$ $\left.\mathbf{u}^{0}+\delta \mathbf{u}\right)$ with the unperturbed wavefield satisfying the unperturbed wave equation

$$
\rho_{0} \ddot{u}_{i}^{0}=\left(\lambda_{0}+\mu_{0}\right)\left(\nabla \cdot \mathbf{u}^{0}\right)_{, i}+\mu_{0} u_{i, j j}^{0}
$$

Assuming that the scattered wavefield is much weaker than the unperturbed wavefield this gives the first-order Born approximation by discarding higher-order terms:

$$
\rho_{0} \delta \ddot{u}_{i}-\left(\lambda_{0}+\mu_{0}\right)(\nabla \cdot \delta \mathbf{u})_{, i}-\mu_{0} \nabla^{2} \delta u_{i}=Q_{i}
$$

with $Q_{i}$ being a term of the unperturbed wavefield and the perturbed model parameters which is given as equation 13.22 in Aki \& Richards (2002).

$$
Q_{i}=-\delta \rho \ddot{u}_{i}^{0}+(\delta \lambda+\delta \mu)\left(\nabla \cdot \mathbf{u}^{0}\right)_{, i}+\delta \mu \nabla^{2} u_{i}^{0}+(\delta \lambda)_{, i}\left(\nabla \cdot \mathbf{u}^{0}\right)+(\delta \mu)_{, j}\left[u_{i, j}^{0}+u_{j, i}^{0}\right]
$$

with $\mathbf{u}^{0}$ being a solution for the unperturbed medium.

Assuming Rayleigh scattering, where the wavelength of the incident wavefield is much larger than the scale of the heterogeneity, the scattering problem reduces to a point scatterer and the full scattered wavefield is approximated by that of an array of point scatterers. Following Wu \& Aki (1985), it is possible to derive expressions for the equivalent point source in Rayleigh scattering. These expressions also contain the directivity of the radiation of the scattered wavefield, and are provided as equations (7) to (10) in Frederiksen \& Revenaugh (2004). This gives us the ability 
to use both the amplitude and radiation pattern of scattering from small-scale heterogeneities in solving the forward problem of the waveform inversion.

We assume the incident $P$-wave to be planar (Fig. 2) with a known slowness vector, a condition well met for teleseismic records. The scattered wavefield is derived from the seismic observations by computing the 3 -component receiver functions relative to the first arriving $P$ wave. The considered input seismic wavefield includes the direct incident $P$ and the free-surface reflections $(P p$ and $P s)$, producing forward and backscattering in the volume, respectively. The forward and backscattering of the input wavefield produces six possible scattered phases (where $\bullet$ indicates the scattering event along the raypath) at small-scale elastic heterogeneities: $P \bullet p, P \bullet s, P p \bullet p, P p \bullet s$, $P s \bullet p$ and $P s \bullet s$. In the forward modelling, we consider every possible combination of perturbed parameter $\left(V_{P}, V_{S}, \rho\right)$, incident wave (forward scattering $P$ and backscattering free surface reflection $P p$ and $P s)$ and station location. The inclusion of the free surface backscattered energy as well as the forward scattered direct wave increases the resolution of the study volume and allows us to resolve a 3D perturbation model, here represented as a regular grid of perturbed cells. We use ray tracing in a 1D velocity model to determine traveltimes to and from the scattering heterogeneity and for incidence and refraction angles. We use equations (7) to (10) of Frederiksen \& Revenaugh (2004) including a geometrical spreading factor for a layered medium to determine the amplitudes of the scattered energy in an elastic velocity model.

The Born approximation prescribes that single scattered waves propagate in the unperturbed medium and do not interact with heterogeneities again. Therefore, the scattered wavefields from individual heterogeneities are independent, which allows the simple summation of the contributions of individual heterogeneities to calculate the complete scattered wavefield $T$

$$
T=\sum_{i=1}^{N} \sum_{j=1}^{3} t_{i j}
$$

with $t_{i j}$ representing the time series representing the scattering contribution of the $j$ th perturbed parameter of the $i$ th scatterer (Frederiksen \& Revenaugh, 2004).

The medium beneath the array is parameterised into a 3D grid of cells with each cell potentially containing a perturbation of elastic parameters. The perturbation for all cells can be collapsed in 


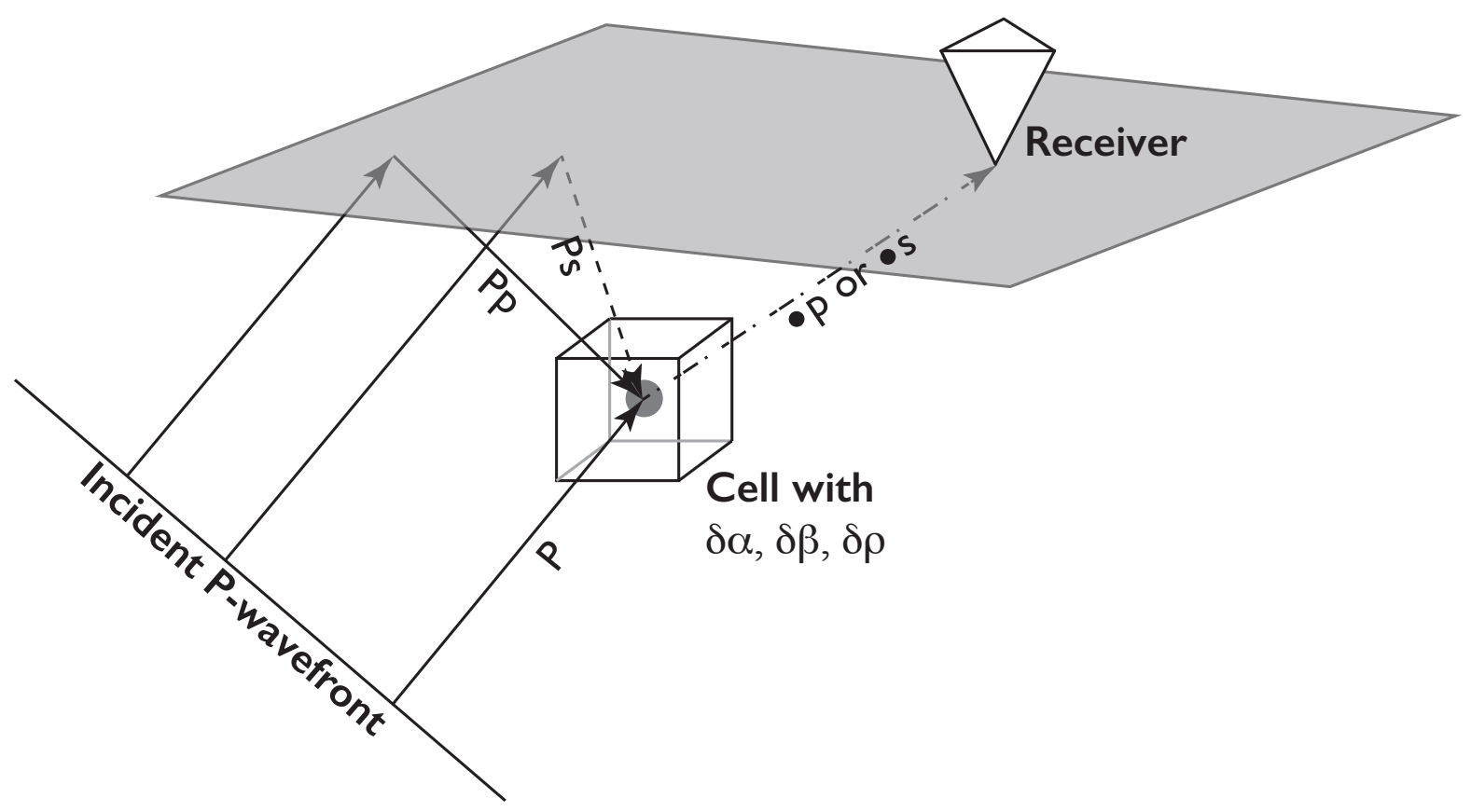

Figure 2. Sketch of the scattered phases included in the full waveform inversion. An incoming planar $\mathrm{P}$-wave wavefront interacts with a cell with a parameter disturbance $(\delta \alpha, \delta \beta, \delta \rho)$ either from the direct wavefront (forward scattered) or the back-scattered wave from the free-surface reflection. The wavetype can convert upon scattering from $\mathrm{P}$ to $\mathrm{S}$.

an $\mathrm{M}$-element vector $\mathbf{m}$ with dimension $\mathrm{M}=\#$ cells in $[x, y, z] \times$ properties $[\Delta \alpha, \Delta \beta, \Delta \rho]$. Summing over all contributing elements we obtain the $\mathrm{N}$-element vector $\mathrm{d}^{i}$ with the number of points depending on $\mathrm{N}=$ samples $\times$ stations $\times$ components $\times$ events. The dependence of the full scattered wavefield on arbitrary model $\mathbf{m}$ is then described as

$$
\mathbf{d}=\mathbf{A m}
$$

A is an $\mathrm{N} \times \mathrm{M}$ matrix describing the sensitivity of each data point to each model parameter, i.e. each column of A represents a differential seismogram for a perturbation of a single parameter in a single cell of the perturbed model. Equation (7) is linear and can therefore be solved using linear inverse theory. To pose this problem as a damped inversion the inverse problem is formulated as a minimization: 


$$
\min \left\|\left[\begin{array}{l}
\mathbf{A} \\
\lambda \mathbf{I}
\end{array}\right] \mathbf{m}-\left[\begin{array}{l}
\mathbf{d} \\
0
\end{array}\right]\right\|_{2}
$$

with $\mathbf{I}$ being an MxM identity matrix and $\lambda$ a weighting factor, representing uniform damping. We use the LSQR method (Paige \& Saunders, 1982) to solve for the material properties in $\mathbf{m}$. For the inversion of real data it has been found that regularisation by smoothing is preferable to damping (Frederiksen \& Revenaugh, 2004) as it provides results with higher coherence. Using LSQR, the model is smoothed by posing $\mathbf{m}=\mathbf{S x}$ with $\mathbf{S}$ being a matrix containing a Gaussian smoother. We use $\mathbf{B}=\mathbf{A S}$ and the minimization

$$
\min \left(\|\mathbf{B} \mathbf{x}-\mathbf{d}\|^{2}+\lambda^{2}\|\mathbf{x}\|^{2}\right)
$$

in which we solve for $\mathbf{x}$ rather than $\mathbf{m}$ (Van der Lee \& Nolet, 1997; Frederiksen \& Revenaugh, 2004). For all recovery tests and real data inversions, we apply a moving Gaussian smoother with a standard deviation of one model element in the horizontal directions, but we do not smooth in the vertical direction. No smoothing is applied beyond three standard deviations. This choice biases the recovered model towards lateral coherence, making recovered lateral changes more coherent in our study region where we expect strong lateral changes across the NAFZ.

The model space is parameterised as a regular grid with $5 \mathrm{~km}$ horizontal grid spacing and $2 \mathrm{~km}$ vertical grid spacing with $30(0-29)$ cells in horizontal directions and $60(0-59)$ in vertical direction. Each cell is treated as a point scatterer with vertical and horizontal locations at depths $2 \cdot j \mathrm{~km}(j=$ $0, \ldots, 59)$ and longitude/latitude location of $5 \cdot k(k=0, \ldots, 29)$, respectively. The maximum grid size is controlled by the maximum memory required to invert the dataset (see below). We tested the method with doubled lateral and vertical grid spacing and do not find noticeable differences in the general structure of the solutions except for obvious impacts on the maximum possible resolution of the solutions. 


\section{DATA}

We use passive seismic data from stations of the Dense Array for Northern Anatolia (DANA) that were installed across the NAFZ in the region of the 1999 İzmit and Dücze ruptures (DANA, 2012). DANA was deployed between May 2012 and October 2013 and stations were arranged in a quasi-rectangular region of $35 \mathrm{~km}$ by $70 \mathrm{~km}$ with a nominal station spacing of $7 \mathrm{~km}$ (Fig. 1). Stations were aligned along seven north-south oriented lines (labelled A to F) and 11 east-west lines (labelled 01 to 11 ). Seven additional stations were installed in an eastern semi-circle with a radius of about $60 \mathrm{~km}$. Three permanent stations (SPNC, SAUV, GULT) of Boğaziçi University and Kandilli Observatory and Earthquake Research Institute/National Earthquake Monitoring Center (BU-KOERI/NEMC) located within the DANA network grid were included in the analysis. Stations were equipped mainly with Güralp CMG-6TD and CMG-3T medium broadband and broadband three-component instruments (full information on the network can be found in DANA (2012)). Data were sampled at $50 \mathrm{~Hz}$.

We use earthquakes within the deployment period with $\mathrm{m}_{b}>5.5$ from the catalogue of the National Earthquake Information Centre (NEIC) and angular distances of $30^{\circ}$ to $90^{\circ}$. For the permanent stations we add events from 2009 onwards (in total 47 additional events contributing typically a single 3-component seismogram (ZRT) to the dataset). Low frequency noise was suppressed by applying a 2-way, 2-pole high-pass filter with cut-off frequency of $0.1 \mathrm{~Hz}$. We calculate 3-component receiver functions (RFs) with a maximum frequency of $1.2 \mathrm{~Hz}$ using the time domain iterative deconvolution approach by Ligorría \& Ammon (1999) deconvolving the Z component from the vertical, radial and transverse components. The calculated receiver functions were visually inspected to select events following these criteria: (1) transverse RFs show lower or comparable amplitudes than radial RFs, (2) the direct $P$-wave arrival is close to the predicted travel time for a 1D Earth model and (3) no evidence for large amplitude ringing. The pre-processing used to obtain the receiver functions is similar to the method used by Kahraman et al. (2015), but applied to all three components (vertical, radial, transverse) of the traces in our analysis. To remove the first arrival, which does not contain any additional structural information, we mute the first $2.5 \mathrm{~s}$ of each trace following the theoretical $P$-wave arrival. 


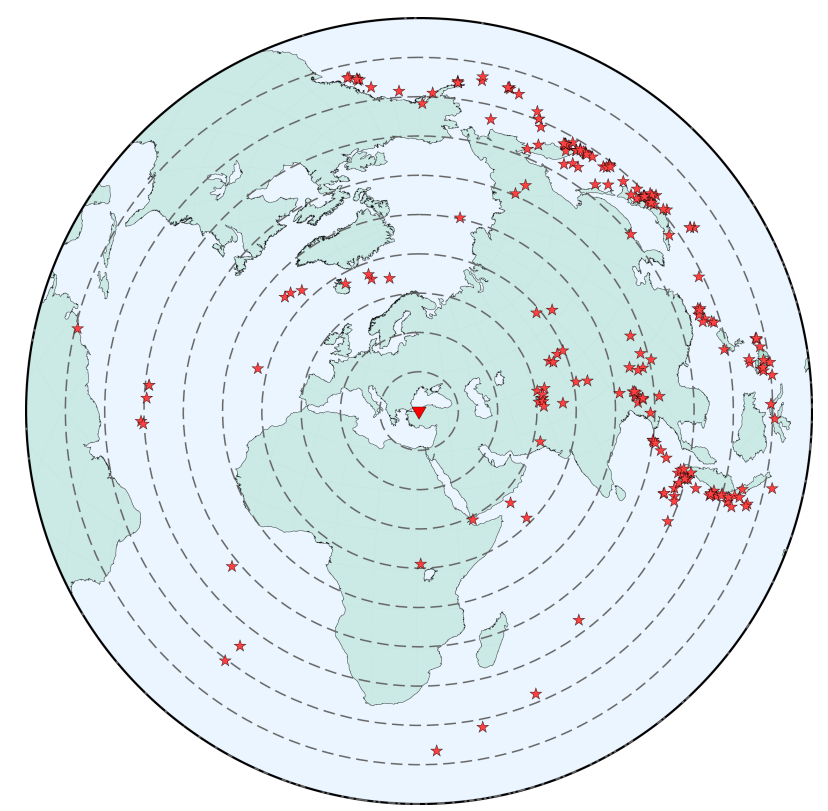

Figure 3. Earthquake locations relative to the center of the DANA array. Dashed circles give distance from DANA center ni $10^{\circ}$ steps. Earthquakes with $\mathrm{m}_{b}>5.5$ occurring during the deployment and since 2009 for the permanent stations in an epicentral distance of $30^{\circ}$ to $90^{\circ}$ were used in the analysis.

In total, we use 1396 traces from 176 events in our analysis. The distribution of sources is shown in Figure 3. Traces were cut and tapered to $100 \mathrm{~s}$ and downsampled to $5 \mathrm{~Hz}$ (from the original $50 \mathrm{~Hz}$ sampling). Despite the downsampling, the matrix to invert is very large which limits the achievable resolution and model depth. Typical storage requirements for the matrix inversion using the sparse storage method are $\approx 338 \mathrm{~Gb}$ for a model space dimension $(\mathrm{x} \times \mathrm{y} \times \mathrm{z}) 145 \times 145$ $\times 118 \mathrm{~km}^{3}$ with an element size of $5 \times 5 \times 2 \mathrm{~km}^{3}$ and 1396, $100 \mathrm{~s}$ long traces, sampled at $5 \mathrm{~Hz}$. We are able to invert the full dataset without reverting to inverting subsets of data and stacking the resulting images (Frederiksen \& Revenaugh, 2004; Zhang \& Frederiksen, 2013) leading to improved image quality of our results.

\section{RECOVERY TESTS}

We tested several background velocity models for data inversion and synthetic data recovery including models by Karahan et al. (2001), Bekler \& Gürbüz (2008), and Horasan et al. (2002) and models including constant velocity and linear vertical gradients. The background models are used 


\begin{tabular}{cccc}
\hline Depth $(\mathrm{km})$ & $\mathrm{V}_{P}(\mathrm{~km} / \mathrm{s})$ & $\mathrm{V}_{S}(\mathrm{~km} / \mathrm{s})$ & $\rho\left(\mathrm{kg} / \mathrm{m}^{3}\right)$ \\
\hline $0-2$ & 3.6 & 1.967 & 2.376 \\
$2-14$ & 5.900 & 3.225 & 2.814 \\
$14-26$ & 6.500 & 3.552 & 2.955 \\
$26-40$ & 7.000 & 3.691 & 2.975 \\
$\vdots$ & 8.055 & 4.347 & 3.326 \\
\hline
\end{tabular}

Table 1. 1D velocity model used in inversion. Depth, $P$-wave, $S$-wave and density $(\rho)$ following (Karahan et al., 2001)

for raytracing to determine traveltimes of the incident and scattered wavefield. While timing of arrivals changes slightly for all realistic velocity models, the overall recovered structure in our tests does not depend significantly on the choice of background model, although depths of interfaces change due to changes in the traveltimes. We chose to use the model by Karahan et al. (2001) for all inversions presented here (Table 1, Fig. 4). This velocity model is derived from seismic experiments in the study area and has been used in previous studies using this dataset (Kahraman et al., 2015; Altuncu Poyraz et al., 2015).

Figure 5 shows the result of an inversion of the full (1396 traces) noisy synthetic data generated through the perturbation model shown in Fig. 4b). A sub-set of the synthetic traces used in this inversion, i.e. the stations recording event 20123211812 and used in the data inversion, are shown in Fig. 4a) and d). Synthetic data were generated using ray tracing through the background velocity model with the addition of the scattered wavefield (i.e. the summation of all contributions of the single scatterers in the model). We use a $0.25 \mathrm{~s}$ wide Gaussian wavelet as the source time function. Synthetic tests use the source-receiver combinations for each event in the dataset, therefore recreating the same resolution as the recorded dataset. For comparison we show the recorded data in Fig. 4a) with the first arrival muted. Scattered phases can be seen coherently across the traces. The synthetic traces (Fig. 4c) show similar structure although clearly are not able to capture the full complexity of the data due to the simplicity of the model (Fig. 4b). Noise is added to the synthetic data through a random number generator (Marsaglia \& Bray, 1964) using 10\% RMS 

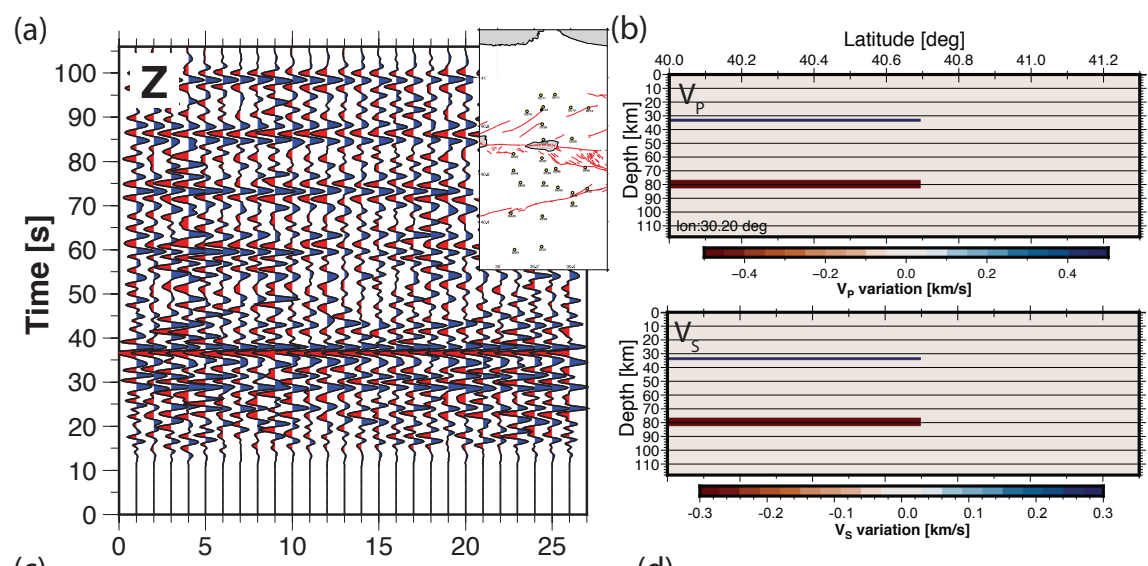

(c)

(d)
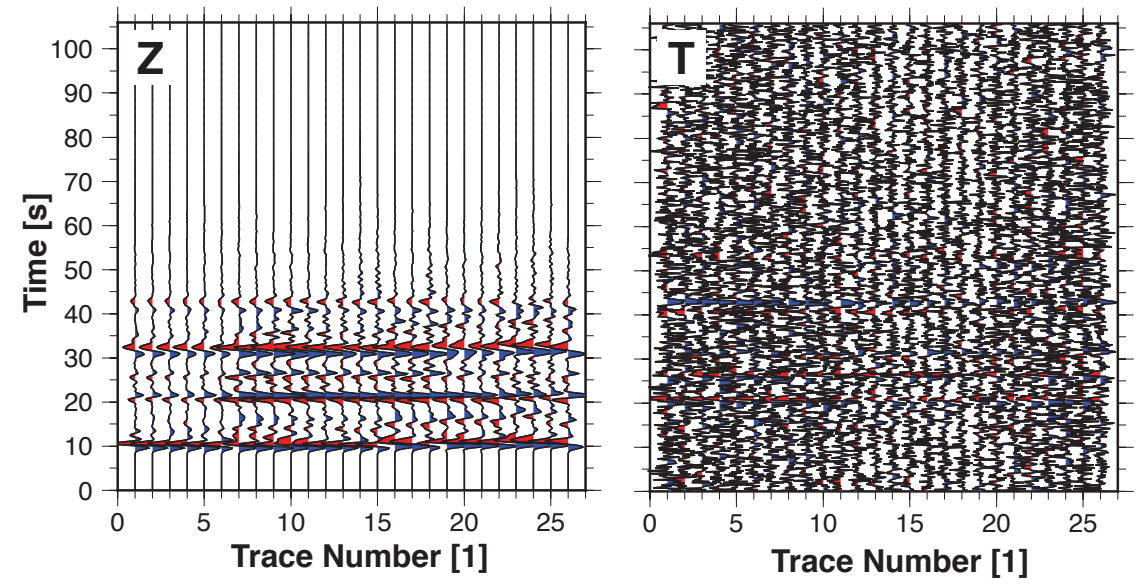

Figure 4. Example data and synthetics. (a) Recorded data example of vertical component of event 20123211812 (insert shows station configuration). Data are cut to $100 \mathrm{~s}$ and tapered. The direct P-arrival is suppressed. (b) North-South slices through perturbation model to calculate synthetics. (c) Noiseless synthetics (vertical) through perturbation model shown in b), including all scattering events from direct wave and free surface reflections. Synthetics represent the event-station configuration of the quality-controlled receiver functions for event 20123211812 shown in a). Although the perturbation is not continuous throughout the model, the scattered wavefield can be recorded across the network with distinctive moveout allowing the localisation of the perturbation. (d) Transverse component of the synthetic data calculated for model shown in (b) with added noise. We add Gaussian noise with a $10 \%$ standard deviation relative to the maximum signal amplitude to the synthetic data.

amplitude variation Gaussian noise compared to the direct wave amplitude to produce this noisy synthetic dataset (Fig. 4d).

The synthetic model is parameterised with $5 \mathrm{~km}$ cell spacing horizontally and $2 \mathrm{~km}$ vertically. The model contains a $V_{P}=+0.5 \mathrm{~km} / \mathrm{s}$ and $V_{S}=+0.3 \mathrm{~km} / \mathrm{s}$ anomaly for a single depth element $(2 \mathrm{~km})$ starting at $34 \mathrm{~km}$ depth and a $V_{P}=-0.5 \mathrm{~km} / \mathrm{s}$ and $V_{S}=-0.3 \mathrm{~km} / \mathrm{s}$ anomaly with thickness 

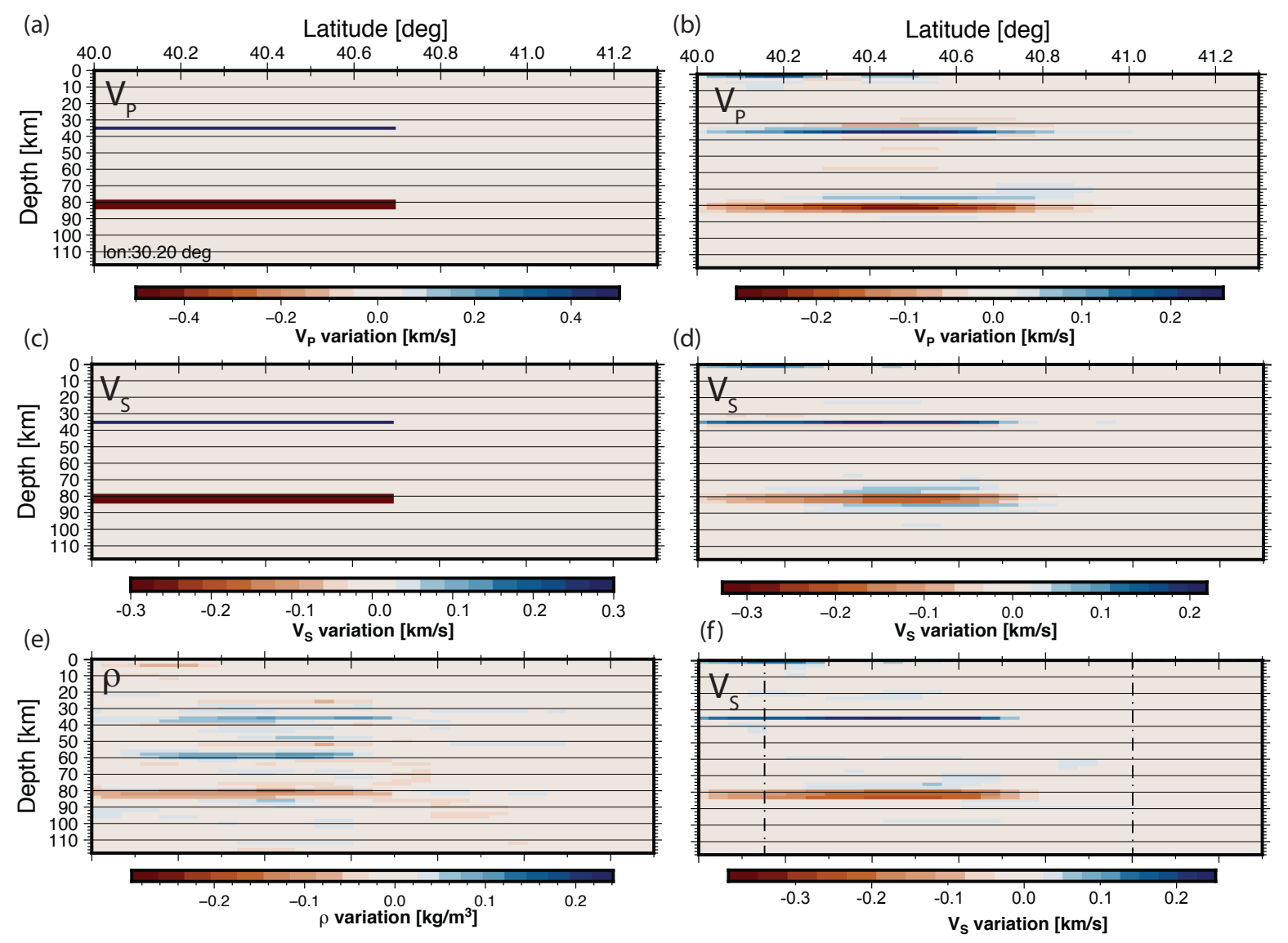

Figure 5. Recovery tests for model shown in Fig. 4 containing heterogeneous $V_{P}$ and $V_{S}$ structure. Slices were taken from the $3 \mathrm{D}$ model at longitude $30.2^{\circ}$. (a) $V_{P}$ anomaly of input model containing terminating velocity anomalies at $32 \mathrm{~km}$ (negative) and $76 \mathrm{~km}$ (positive). Anomaly strength is $\pm 0.5 \mathrm{~km} / \mathrm{s}$. (b) Recovered model after scattering inversion. Due to damping the velocity recovered is smaller than the input model but locations are well resolved. Horizontal smoothing of a single lateral element (5 km) is applied. (c) as (a) but for $V_{S}$. Velocity anomaly is $\pm 0.3 \mathrm{~km} / \mathrm{s}$. (d) As (b) but for $V_{S}$. (e) Recovered low amplitude density $(\rho)$ anomaly after inversion. Input model does not contain density variations so recovered anomaly represents cross-talk between the different components. (f) Wiener filtered longitude slice of recovered model to fit recovered depth of anomaly as a zero-phase wavelet. Black dashed lines in f) indicate the perceived limits of the well-resolved region. of $6 \mathrm{~km}$ starting at $78 \mathrm{~km}$ (Fig. 5 a and c). No density variation was added to the model. The anomalous layers extend across the model in longitude but terminate $80 \mathrm{~km}$ into the model from the south (approximately at $40.7^{\circ} \mathrm{N}$ ), leaving the part of the model that corresponds to the Istanbul zone free of a velocity anomaly. The inverted model in Fig. $5 \mathrm{~b}$ and $\mathrm{d}$ shows the recovery of the input model. Because the inversion uses the Born approximation, which generates signals 
from localized perturbation, the recovered model will be a band-pass filtered version of the input. We apply a Wiener optimum filter to minimize the effects of the inversion process, mainly to reduce sidelobes to aid interpretation. The optimization filter, as described for example by Gubbins (2004), is obtained by minimising the residual between the desired output $g_{t}$ (Fig. 5a,c) and the signal obtained by convolution of the filter $f_{t}^{0}$ with the actual output $x_{t}$ (Fig. 5b,d)

$$
\left(e_{t}\right)^{2}=\left(g_{t}-x_{t} * f_{t}^{0}\right)^{2}
$$

The effect of the inversion and the filter terms acting on a single trace of the synthetic model are shown in Supplemental Figure S1. Although the input model in this test does not contain any density $(\rho)$ heterogeneity, Fig. 5e shows that the inverted model for the density structure is affected by cross-talk between the different parameters (more examples given in Supplemental Figure S2). However, relative amplitudes $\Delta \rho$ in this model are small and the effect is most prominent in areas with velocity anomalies. Tests with models including $\Delta \rho$ show that density structure can be resolved. Complete input and output models for this recovery test and further recovery tests are shown in the Supplemental Figures S2 to S7.

These tests show that the recovery of velocity and density anomalies is variable within the model volume due to the relative sampling of the model volume by the ray configuration of the dataset. Peripheral regions are generally less well resolved than the center of the volume (Fig. 5). Within the central zone we do not observe strong depth or amplitude variations of the recovered model, adding confidence to our interpretation. Areas of the model space that are not well resolved are masked in all following figures (and supplemental material) and the approximate limits of the well-resolved volume are shown in the N-S profiles (dot-dashed vertical lines in Fig. 5f), to which we limit our interpretation.

Changing the depth of the inverted model space between $48 \mathrm{~km}$ and $118 \mathrm{~km}$ (in $20 \mathrm{~km}$ steps) does not lead to strong changes in the inverted model. A comparison between a $48 \mathrm{~km}$ and $118 \mathrm{~km}$ deep model containing the same structure for $V_{P}$ and $V_{S}$ is shown in supplemental Figure S3 a) and $b$ ). This holds even when synthetic traces were generated including structure below the inverted volume (Fig. S3c) showing that heterogeneities underneath the volume are not erroneously 
mapped into the model volume. We show models down to depths of $118 \mathrm{~km}$ (60 nodes with $2 \mathrm{~km}$ spacing) in a trade-off between achievable resolution, model size and required computer memory. The horizontal smoothing leads to some smearing of energy in horizontal directions. Nonetheless, Fig. 5 shows that terminating discontinuities can be accurately located within 1 to 2 horizontal elements (i.e. 5 to $10 \mathrm{~km}$ ) in the central region of the model space. We also performed recovery tests using other structural models including velocity and density heterogeneities to better understand the performance of the method (see Supplemental Material).

\section{RESULTS}

The results of the tomographic scattering inversion of the DANA dataset are shown in Fig. 6 and Fig. 7. Slices in Fig. 6 and 7 were extracted from the three-dimensional inversion volume along North-South (Fig. 6) and East-West (Fig. 7) profiles at locations shown in Fig. 1. The locations of the profiles were chosen to be in similar locations to those shown in Fig. 6 of Kahraman et al. (2015) (for an equivalent display to Kahraman et al. (2015) see Supplemental Figure S8, S10 and S12). Full solutions are presented in the form of animated GIFs in Figures S14 and S15 of the Supplemental Materials. The model is filtered with the Wiener optimization filter as discussed above.

Generally, the $S$-wave images show greater amplitude and are better constrained due to the combination of upgoing $P s$ conversions as well as the free-surface multiples, while the $P$-wave inversion solely relies on the free-surface multiples. The $S$-wave tomographic images also seem to show more fine scale structure likely related to the shorter wavelength. The density $(\Delta \rho)$ profiles show some of the major structure and are shown in the supplemental Figs. S12 and S14 but suffer from cross-talk as shown earlier. As the interpretation of the $\Delta \rho$ profiles is more difficult and there is no independent constraint on the density structure we do not discuss this parameter further in the text. 


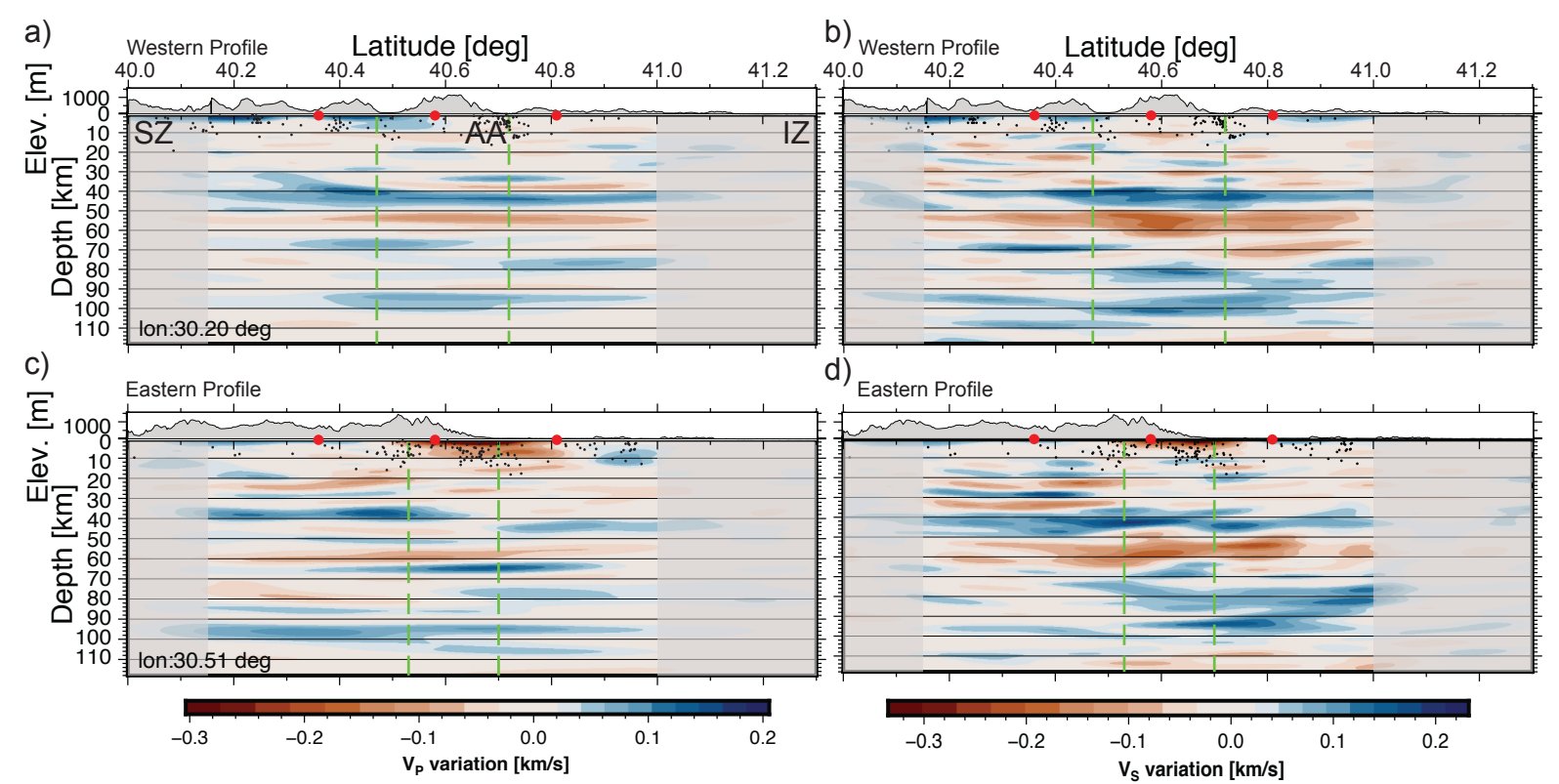

Figure 6. North-south oriented slices along $30.2^{\circ}$ (top) and $30.51^{\circ}$ (bottom) for the inversion for $\mathrm{V}_{P}$ (left) and $\mathrm{V}_{S}$ (right) structure. Profile locations are indicated in Fig.1. Approximate locations of the southern and northern branches of the NAFZ are shown as dashed green lines. Areas with limited resolution as determined from the recovery tests (Fig. 5) are masked in grey. Red dots indicate locations of EW slices shown in Fig.7. Black circles indicate local seismicity as determined by Altuncu Poyraz et al. (2015) within $\mathrm{a} \pm 5 \mathrm{~km}$ corridor projected onto the profile. The top panel in each subpanel shows SRTM topography along the profile (Farr et al., 2007).

\subsection{Western Profile}

Profiles for $V_{P}$ (Fig. 6 a) and $V_{S}$ (Fig. 6 b) have been extracted along a longitude of $30.20^{\circ}$ E.

Areas with limited resolution as determined from the recovery tests (Fig. 5) have been masked in this profile in transparent grey. The $V_{P}$ profile (Fig. 6a) is dominated by a velocity increase at $\sim 40 \mathrm{~km}$ depth for most of the profile, which we associate with the Moho. Depths to interfaces are shallower velocity increase located at $\sim 32 \mathrm{~km}$ depth deepening to $40 \mathrm{~km}$ at $\sim 40.4^{\circ} \mathrm{N}$. The anomaly also seems to fade, i.e. showing less of a velocity anomaly, south of about $40.3^{\circ} \mathrm{N}$. The point of bifurcation coincides with the surface expression of the southern strand of the NAFZ. A similar Moho signal is observed in the $S$-wave anomaly at $\sim 40 \mathrm{~km}$, shallowing to about $38 \mathrm{~km}$ within the Armutlu block, which shows a thickening of this interface. The $S$-wave anomaly does not show 
the same shallow branch observed in the P-waves but shows lower amplitudes south of $\sim 40.4^{\circ} \mathrm{N}$, i.e. south of the southern NAFZ strand.

Observed crustal structure includes a weak high $V_{P}$ anomaly at $\sim 18 \mathrm{~km}$ in the Armutlu block with weak complex $V_{S}$ structure in the Sakarya zone. Complex structure starting at $\sim 32 \mathrm{~km}$ depth (positive and negative anomalies) in $V_{P}$ and $V_{S}$ can be seen in the vicinity of the northern strand $\left(40.7^{\circ} \mathrm{N}\right)$ just overlying the Moho. The $V_{P}$ model shows less structure in the upper crust except a fast anomaly to depths of $\sim 5 \mathrm{~km}$ around the southern branch and a slow (also seen in $V_{S}$ ) overlying fast anomaly between $\sim 10 \mathrm{~km}$ and $\sim 20 \mathrm{~km}$ depth in the Armutlu block.

The high velocity anomaly at $40 \mathrm{~km}$ depth is underlain by a strong low $V_{P}$ and $V_{S}$ anomaly at depths of $\sim 50 \mathrm{~km}$. This anomaly shows lower amplitudes in the Sakarya Zone with the change coinciding with the surface expression of the southern NAFZ strand. We also identify a velocity increase in $V_{P}$ and $V_{S}$ at $\sim 64 \mathrm{~km}$ and $\sim 66 \mathrm{~km}$ depth, respectively, around $40.4^{\circ} \mathrm{N}$ (southern strand) and $\sim 74 \mathrm{~km}$ in $V_{P}$ beneath the Istanbul zone (with a termination at the northern strand). The $V_{S}$ anomaly shows a low velocity anomaly at $\sim 68 \mathrm{~km}$ depth just north of the northern strand changing to a high velocity anomaly at $\sim 74 \mathrm{~km}$ depth north of $40.9^{\circ} \mathrm{N}$.

At greater depths we observe a fast anomaly in $V_{S}$ at $\sim 78 \mathrm{~km}$ depth and a fast anomaly in $V_{P}$ and $V_{S}$ at $\sim 92 \mathrm{~km}$ but showing depth variation in $V_{S}$. The $78 \mathrm{~km}$ anomaly seems to merge with the deeper anomaly in the Istanbul zone.

\subsection{Eastern Profile}

The eastern North-South profile at $30.51^{\circ} \mathrm{E}$ (Figs. 6c and 6d) shows more structure, especially in the crust, than the western profile despite the close proximity of the two profiles.

We observe a strong, fast $V_{P}$ anomaly at a depth of $\sim 34 \mathrm{~km}$ terminating halfway through the Armutlu block and re-emerging at a depth of $\sim 42 \mathrm{~km}$ just north of the northern strand in the Istanbul zone. In $V_{S}$ we observe a more continuous structure with a high velocity anomaly at $\sim 36 \mathrm{~km}$ depth in the south stepping to $\sim 42 \mathrm{~km}$ at $\sim 40.7^{\circ} \mathrm{N}$ coinciding with the northern strand. The $V_{P}$ anomaly is weak in the Armutlu block on this profile and seems to terminate at $40.6^{\circ} \mathrm{E}$, 
while the $V_{S}$ anomaly is more continuous, but also weakens in this region. The amplitude variation of these anomalies cannot be explained by the limitations of the sampling (see Fig. 5).

Especially striking in this profile is the complex $V_{S}$ structure in the Sakarya Zone down to depths of about $30 \mathrm{~km}$ manifesting as series of fast and slow anomalies between $\sim 10 \mathrm{~km}$ and $32 \mathrm{~km}$ (see supplemental Figure S7). The $V_{P}$ structure is similar but weaker than $V_{S}$. The structure terminates abruptly at the southern strand with little crustal structure in the Armutlu block. The Adapazarı basin (centred at about $40.7^{\circ} \mathrm{N}$ ) is representing as a low velocity anomaly between $40.6^{\circ} \mathrm{N}$ and $40.7^{\circ} \mathrm{N}$ to depths of about $6 \mathrm{~km}\left(V_{S}\right)$.

Similar to the western profile we identify a slow anomaly in both $V_{P}$ and $V_{S}$ at depths of $\sim 56 \mathrm{~km}$ and $\sim 52 \mathrm{~km}$, respectively. The $V_{S}$ anomaly seems to show more complexity. We identify a slow anomaly at $\sim 76 \mathrm{~km}$ depth in the Sakarya zone in $V_{P}$ which cannot be identified in $V_{S}$. This anomaly seems to terminate at the southern branch. Fast anomalies are detected at $\sim 92 \mathrm{~km}$ in $V_{P}$ and $V_{S}$ across the profile with shallower fast anomalies for $V_{P}$ and $V_{S}$ at $\sim 76 \mathrm{~km}$ depth beneath the Istanbul zone and the Armutlu block. In $V_{P}$ there is evidence of this interface splitting into a deeper interface deepening to $\sim 102 \mathrm{~km}$ across the southern strand.

\subsection{Sakarya Zone}

The West-East profile for $V_{P}$ and $V_{S}$ (Figs. 7e and 7f, respectively) has been extracted along $40.36^{\circ} \mathrm{N}$ and is fully located within the Sakarya zone. The Sakarya zone is the southernmost tectonic block in the study region. The inverted scattering tomography model shows a positive anomaly at depths of $\sim 38 \mathrm{~km}$. In $V_{P}$ this interface moves to $\sim 32 \mathrm{~km}$ around $30.6^{\circ} \mathrm{E}$. This anomaly seems rather complex and might be discontinuous. We also identify a laterally limited fast anomaly at $\sim 30 \mathrm{~km}$ between $30.4^{\circ} \mathrm{E}$ and $30.6^{\circ}$ E. Deeper a slow anomaly at about $54 \mathrm{~km}$ depth can be seen that shows a slight step down to about $60 \mathrm{~km}\left(V_{P}\right)$ at about $30.4^{\circ} \mathrm{E}$ and seems complex in $V_{S}$. The western part of the profile shows a fast anomaly at $\sim 68 \mathrm{~km}$, with a slow anomaly at $\sim 78 \mathrm{~km}$ in the east. A fast anomaly at $\sim 98 \mathrm{~km}$ depth $\left(94 \mathrm{~km}\right.$ in $V_{P}$ ) is identified which terminates at $30.2^{\circ} \mathrm{E}$ in $V_{P}$. 


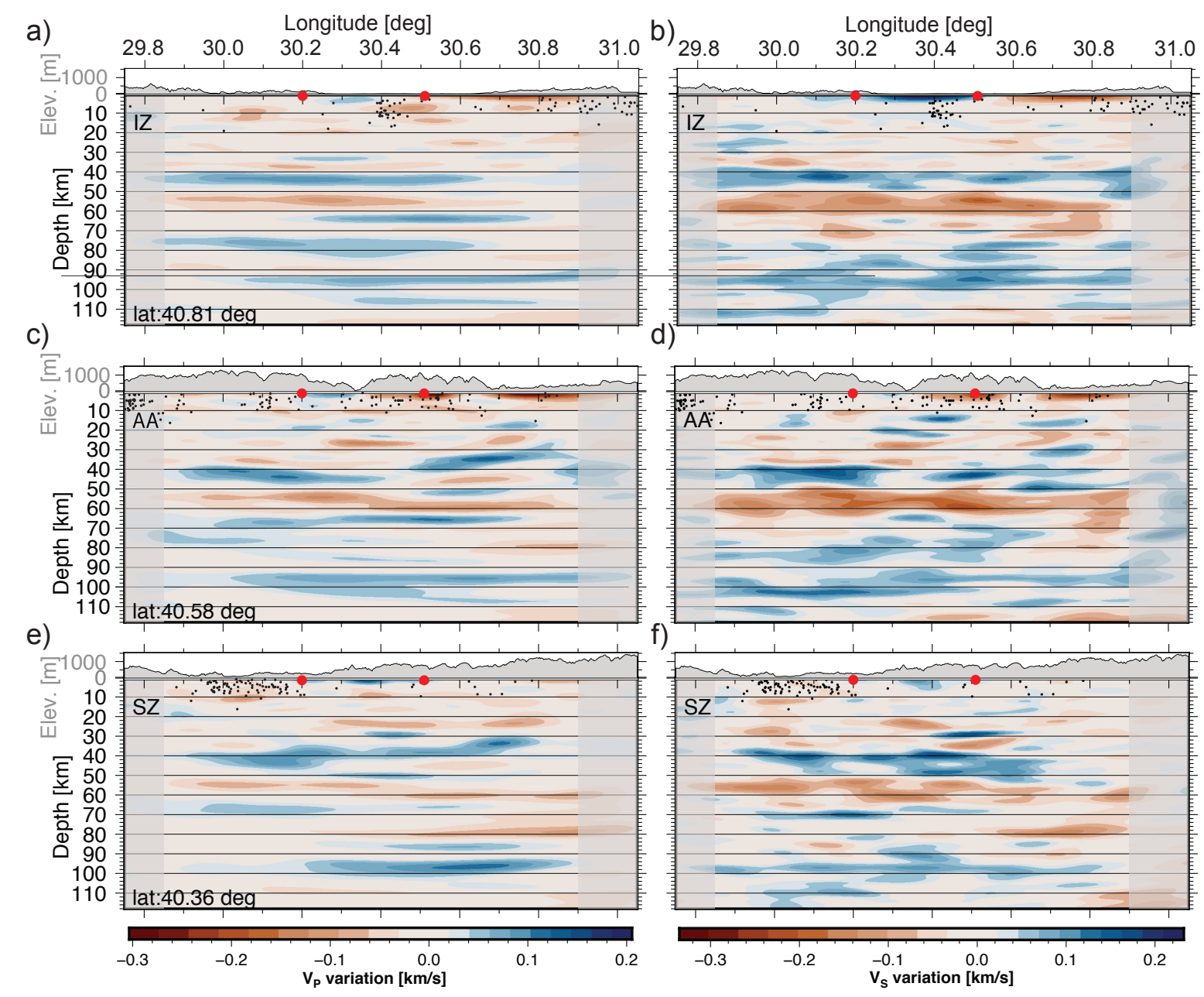

Figure 7. As Fig.6 showing west-east oriented slices through the inverted $\mathrm{V}_{P}$ (left) and $\mathrm{V}_{S}$ (right) structure. Slices are located in the Istanbul zone (IZ - a,b) at longitude $40.81^{\circ}$, the Armutlu-Almacık block (AA $\mathrm{c}, \mathrm{d})$ at $40.58^{\circ}$ and Sakarya zone (SZ - e,f) at $40.36^{\circ}$. Areas with limited resolution as determined from the recovery tests (Fig. 5) masked in grey.

\subsection{Armutlu Block}

In contrast to the Sakarya Zone, the Armutlu Block (Figs. $7 \mathrm{c}$ and $7 \mathrm{~d}$ for $V_{P}$ and $V_{S}$, respectively) $30.4^{\circ} \mathrm{E}$ and appears as shallow as 30 to $32 \mathrm{~km}$ further east in $V_{P} . V_{S}$ also shows the termination but a less pronounced step. The step around $30.6^{\circ} \mathrm{E}$ seems to coincide with the profile moving from the Armutlu block to the Almacik mountains. West of $\sim 30.4^{\circ}$, this interface is underlain by a slow anomaly at $\sim 50 \mathrm{~km}$ showing a step to $\sim 58 \mathrm{~km}$ at $30.4^{\circ} \mathrm{E}$ in $V_{P}$. Overall $V_{S}$ seems more complex. We identify several small scale fast and slow anomalies in the crust, the strongest 


\section{S. Rost et al.}

at $\sim 14 \mathrm{~km}$ around $30.4^{\circ} \mathrm{E}$ in $V_{S}$. Slow anomalies shallower than $40 \mathrm{~km}$ are indicated between $30.5^{\circ} \mathrm{E}$ and $30.9^{\circ} \mathrm{E}$.

A fast anomaly at $\sim 94 \mathrm{~km}$ stretches across most of the profile in $V_{P}$, with comparable bit more complex structure in $V_{S}$. the $V_{S}$ section also shows more localised structures at depths greater than $80 \mathrm{~km}$.

\subsection{Istanbul Zone}

The Istanbul zone (Figs. 7a and $7 \mathrm{~b}$ for $V_{P}$ and $V_{S}$, respectively) shows very little structure down to depths of about $40-42 \mathrm{~km}$ where a strong fast anomaly can be detected in $V_{P}$ and $V_{S}$. This fast anomaly seems to terminate around $30.6^{\circ} \mathrm{E}$ for $V_{P}$ but remains continuous for $V_{S}$. A slow anomaly is visible in $V_{S}$ at depths less than $10 \mathrm{~km}$ between $30.6^{\circ} \mathrm{E}$ and $30.9^{\circ} \mathrm{E}$ and a fast anomaly between $30.2^{\circ} \mathrm{E}$ and $30.5^{\circ} \mathrm{E}$.

The strong Moho signal is underlain by a slow anomaly around $52 \mathrm{~km}$ depth again terminating around $30.6^{\circ} \mathrm{E}$ for $V_{P} . V_{P}$ shows a fast anomaly at $\sim 74 \mathrm{~km}$ depth, which like the Moho signal in this block, terminates at about $30.6 .^{\circ} \mathrm{E}$; the corresponding structure in $V_{S}$ is weaker and discontinuous. A strong fast anomaly at $\sim 92 \mathrm{~km}$ depth can be seen in $V_{P}$ and $V_{S}$, but again the $V_{S}$ structure is complex.

\section{DISCUSSION}

The scattering tomography results show changes in the structure over distances of $5 \mathrm{~km}$. These changes can be related to the different structure of the tectonic blocks and manifest in the NorthSouth profiles. Nonetheless, we observe structural changes in East-West direction where more continuous structure might be expected, at least for the Istanbul and Sakarya zones. The profile across the Armutlu block follows the strike of the NAFZ east of about $30.7^{\circ} \mathrm{E}$ and moves from the Armutlu block to the Almacik Mountains just north of the NAFZ (Fig. 1). The depth slices through the model shown in Fig. 6 and 7 show strong changes between the two north-south trending profiles despite their close proximity. Interpreted NS sections are shown in Fig. 8. To highlight the most coherent part of the model we stack the depth profiles in longitude and divide these at $30.4^{\circ} \mathrm{E}$ to 

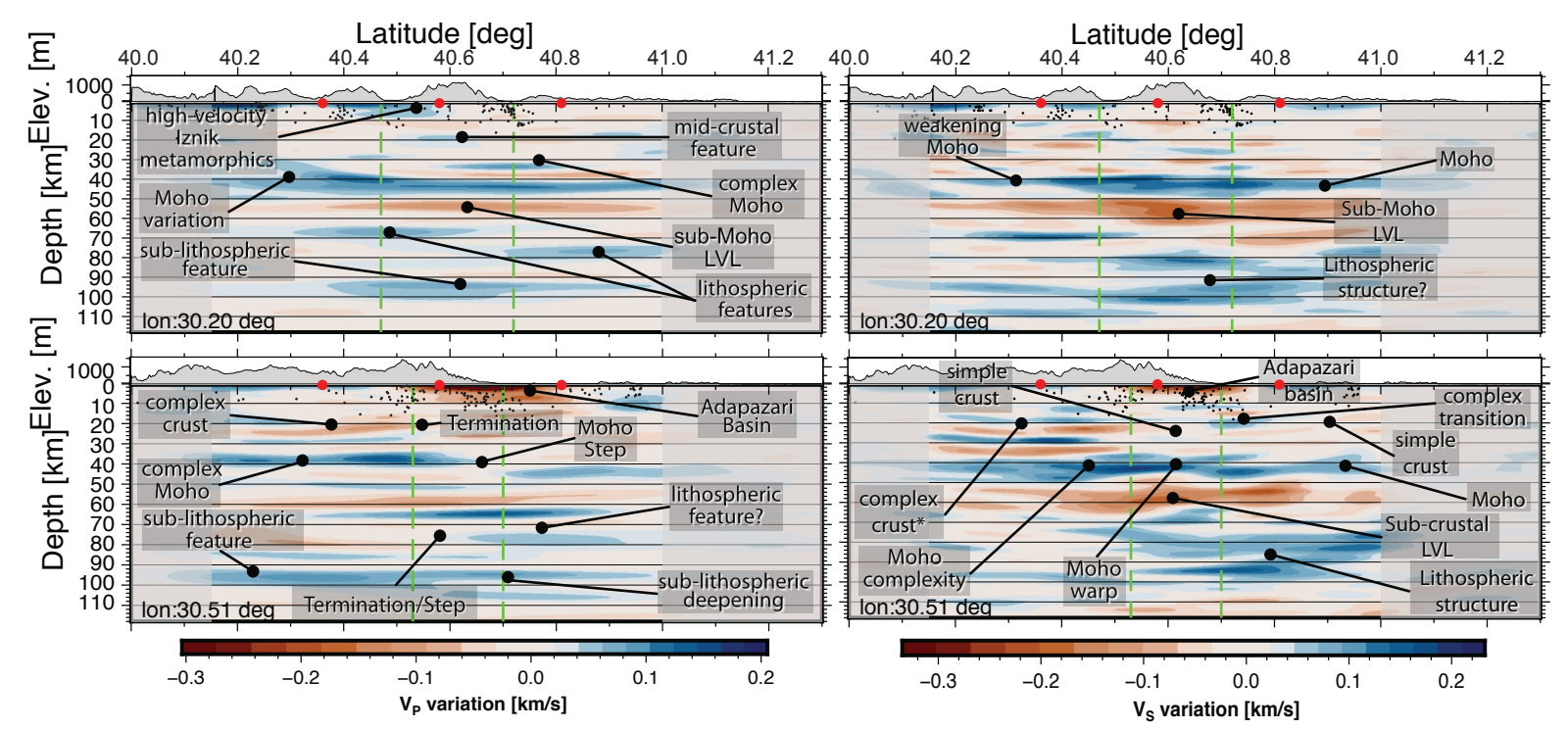

Figure 8. Interpreted NS cross sections for $\mathrm{V}_{P}$ (left) and $\mathrm{V}_{S}$ (right). Shown are North-South oriented slices as in Fig. 6.

show western and eastern stacks in Fig. 9 for both $V_{P}$ and $V_{S}$.

Comparing the individual slices and the stacked velocity-depth profiles shows that many features are coherent along stretches of the profile, but can change on short scale-lengths.

\subsection{Mohorovičic̀ discontinuity}

In the west the Mohorovičic̀ discontinuity (the Moho) is visible in both $V_{P}$ and $V_{S}$ as a dominant fast velocity at depths of $\sim 40 \mathrm{~km}$ with variations in $V_{P}$ in the south and in $V_{S}$ in the Armutlu block. In the east the Moho is shallower in the south $\left(34 \mathrm{~km}\left(V_{P}\right), 38 \mathrm{~km}\left(V_{S}\right)\right)$ but shows a step to larger depths $\left(42 \mathrm{~km}\right.$ ) between $40.6^{\circ} \mathrm{N}$ to $40.7^{\circ} \mathrm{N}$ at $30.51^{\circ} \mathrm{E}$. The deepening of the Moho coincides with the low-velocity region in the teleseismic $S$-wave tomography model by Papaleo et al. (2018) which has been interpreted as the location of the shear zone of the northern branch of the North Anatolian Fault Zone (Fig. 9). The Moho at $30.2^{\circ} \mathrm{E}$ is overlain by a slow anomaly in $V_{P}$ between $40.7^{\circ} \mathrm{N}$ and $40.9^{\circ} \mathrm{N}$ coinciding with the slow anomaly in the traveltime tomography. The corresponding anomaly in $V_{S}$, however extends further south to $40.5^{\circ} \mathrm{N}$ and coincides across that range with both high and low velocity in the traveltime tomography.

In the east the Moho seems much weaker and discontinuous across all three tectonic blocks. 

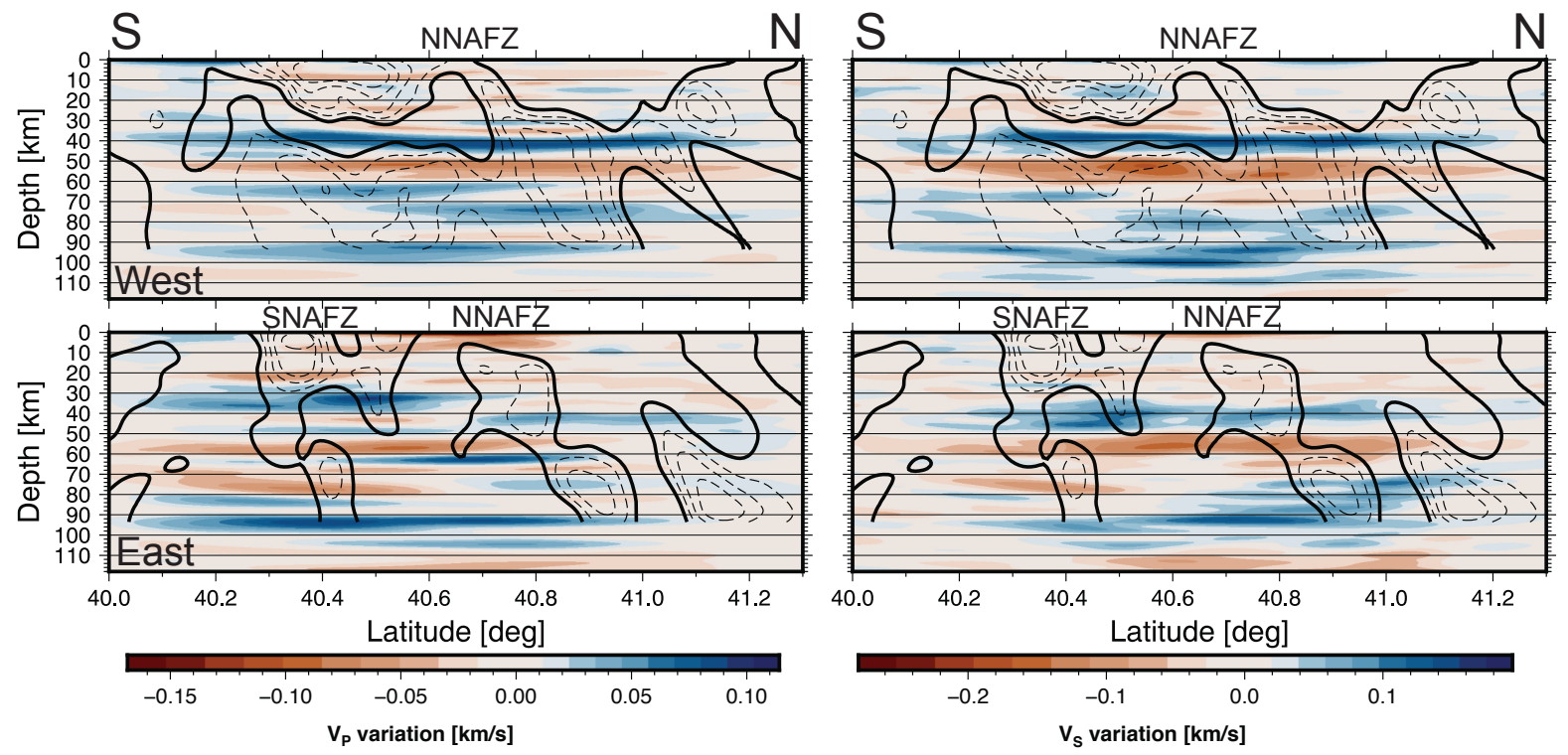

Figure 9. North-South depth slices of the model averaged in longitude (a) for $\mathrm{dV}_{P}$ and (b) $\mathrm{dV}_{S}$. Top figure for each velocity variation is for the western section (west of $30.4^{\circ} \mathrm{E}$ ) of the model with the bottom the eastern part (east of $30.4^{\circ} \mathrm{E}$ ). Contour lines show the $\mathrm{V}_{S}$ tomography of Papaleo et al. (2018) with the $0 \%$ contour line shown as solid and velocity reductions in $0.5 \%$ increments shown as dashed. Teleseismic traveltime tomography Papaleo et al. (2018) contours are shown at $30.2^{\circ} \mathrm{E}$ and $30.4^{\circ} \mathrm{E}$

The strongest change in Moho depth can be identified around $40.8^{\circ} \mathrm{N}$ in the eastern profile where we observe a step from $32 \mathrm{~km}$ to $40 \mathrm{~km}$ coinciding with the tomographically inferred edges of the southern and northern branches of the NAFZ and the surface expression of the northern branch. For the northern branch the fault zone seems to extend into the mantle.

While there are strong north-south changes in the profiles in Figs. 6 to 9 we also observe strong east-west changes, e.g. in the Sakarya zone with a complex Moho structure around $30.5^{\circ} \mathrm{E}$ and the weakening of the Moho east of $30.4^{\circ} \mathrm{E}$ or the change in the Armutlu block at $\sim 30.5^{\circ} \mathrm{E}$, which might be related to the step-over structure of the NAFZ related to the differential movement of the Armutlu and Almackk blocks and the trend of the suture zones between the tectonic blocks. We also observe a pronounced change of the Moho depth between the Armutlu block and the Almacik mountains at around $30.6^{\circ} \mathrm{E}$ (Suppl. Fig. S14, S15), which is more pronounced in $V_{P}$ but also detectable in $V_{S}$, indicating strong contrasts in crustal structure between these two blocks. 


\subsection{Crustal structure}

We find evidence for strong crustal structure variation along some of the profiles. The most striking structure is the apparent strong layering south of the southern branch in the Sakarya zone visible in the north south profiles. This structure is much stronger in the eastern profile for both $V_{P}$ and $V_{S}$ but is dominant in $V_{S}$. The crustal heterogeneity is clearly limited by the surface location of the southern branch and forward models indicate that it consists of a series of high and low velocity anomalies (e.g. Fig. S7) perhaps related to emplacement of magmatic sills during the Tethys closure as have been seen in the eastern Marmara region (Karabulut et al., 2003). The crust in the Armutlu block on the other hand is relatively homogeneous and the heterogeneity is clearly truncated by the southern strand of the NAFZ.

Overlying the Moho in the area of the northern strand along the eastern profiles we detect small-scale, complex Moho structure. Modeling indicates that it could be related to a small-scale heterogeneity with limited extent approximating a point scatterer perhaps related to the material property changes in the fault zone. The lateral smoothing inherent to our inversions leads to a lack of resolution in this case.

We detect evidence for the Adapazarı basin as low velocity anomalies between $40.6^{\circ} \mathrm{N}$ and $40.8^{\circ} \mathrm{N}$ in the eastern profiles. Our method does not allow the necessary depth resolution at these depths for conclusion on the depth of the basin. The high velocity Iznik metamorphics (Taylor et al., 2019) can be detected between $40.4^{\circ} \mathrm{N}$ and and $40.6^{\circ} \mathrm{N}$.

Areas in the proximity of the surface expressions of the northern and southern strand show more heterogeneous structures than areas further away, perhaps related to increased damage around the fault zone (Ben-Zion \& Sammis, 2003). However, the consistency between near surface velocity variation from our inversions and mapped surface structure provides confidence that we can interpret scattered signals from the fault sone as reflecting real structure. We detect a few localized crustal heterogeneities in the Sakarya zone and Armutlu block. There is evidence for a more continuous low velocity anomaly at $\sim 10 \mathrm{~km}$ and $\sim 25 \mathrm{~km}$ depth in the Armutlu block and the Sakarya zone. These are clearer in the $V_{P}$ models. The Istanbul Zone shows very little structure compared 
to the neighbouring tectonic units, which could be related to the absence of metamorphism and the lack of major deformation (Okay, 1989).

\subsection{Sub-crustal structure}

Below the Moho we identify a dominant low velocity layer at depths between $\sim 50$ and $\sim 60 \mathrm{~km}$ in both north-south profiles in $V_{P}$ and $V_{S}$. The low velocity layer weakens but remains observable in the area of a prominent low velocity anomaly in recent tomographic models in this region (Papaleo et al., 2017, 2018) that is linked to the surface expression of the northern strand. This low velocity anomaly in the scattering tomography seems weaker in the Istanbul Zone. The weakening is more pronounced in $V_{P}$ than $V_{S}$. The interface to the anomaly is slightly deeper $(52 \mathrm{~km})$ in the stacked eastern profile but also shows changes in the area of the reduced seismic velocities from traveltime tomography. The continuity of this structure beneath all tectonic blocks, although with possible depth and structural variations, indicates that it is related to lithospheric structure post-dating the amalgamation of northern Anatolia and the development of the suture zones. It is similar to a signal detected by Kahraman et al. (2015) and can be related to anisotropy beneath the Moho related to a lithospheric shear or decoupling zone active during continent amalgamation.

The fast anomalies detected at depths larger than $60 \mathrm{~km}$ shows changes in depth and structure in the vicinity of the surface locations of the NAFZ branches although slightly offset to the north possibly linking mantle structure to dipping fault zones. The shear zone structure might penetrate deep into the lithospheric mantle showing a dip towards the north in agreement with previous results (Kahraman et al., 2015; Papaleo et al., 2017, 2018). The tectonic implications of this northerly dip remain unclear.

There is little evidence for a dominant low velocity anomaly at depths in our model that can be interpreted as a Lithosphere-Astenosphere boundary (LAB). The lower part of the models seems dominated by high velocity anomalies, although there is weak evidence for a low velocity anomaly between 110 and $120 \mathrm{~km}$ depth at the boundary of our model. Therefore we cannot confirm a detection of the Lithosphere-Astenosphere boundary in our models. Lower resolution deeper models 
of the study region do not show evidence for a LAB in our images at greater depth. The LAB might be too gradational to show up as signal in the $P$-wave coda and to be imaged using our method.

\subsection{Shear zones}

In the scattering tomography we see the strongest evidence for the NAFZ shear zone in the abrupt changes of crustal and sub-crustal structures. We see crustal structures that terminate on or near both fault strands, most clearly in the changes of the crustal structure transitioning from the Sakarya Zone to the Armutlu block (i.e. the SNAFZ) which we can trace to the Moho (e.g. Fig. $6 c, d)$. In general the AA shows almost no heterogeneity in the crust. Fig 6 a,b) shows evidence for heterogeneity at crustal depths coinciding with the surface expression of the NNAFZ.

The Moho step detected in the eastern profiles (e.g. Fig 6c, d)) seems to coincide with the surface expression of the NNAFZ and might indicate a localized shear zone extending deeper than the Moho and into the mantle. Some interfaces in the lithospheric mantle (e.g. Fig 6a,c) also show terminations coinciding with the NNAFZ indicating clear sub-Moho structure related to the shear zone.

Other continental continental transform faults such as the San Andreas Fault system (SAF), the Alpine Fault (AF) and the Dead Sea Transform (DST) show similar structures (e.g Weber et al., 2004; Mohsen et al., 2005; Ford et al., 2014; Stern \& McBride, 1998) indicating localized shear throughout the crust as we find in this study. The SAF in southern California (Yan \& Clayton, 2007) and the DST along the Aravia fault (Mohsen et al., 2005) seem to offset the Moho in close proximity to the surface expression of the fault similar to the eastern profiles across the NAFZ. There is evidence that the SAF also offsets the LAB indicating localised shear even in the upper mantle (Ford et al., 2014). Although we do not detect clear arrivals from the LAB, mantle features down to depths of 90 to $100 \mathrm{~km}$ where the LAB has been detected (Kind et al., 2015) could indicate that the shear beneath the NAFZ is localized in the upper mantle similar to the SAF.

Due to the intra-Pontide suture zone located within the study area and the juxtaposition of the tectonic blocks described above it is difficult to separate the potential effects of a suture zone from the shear zone in this locality. The NAFZ seems to exploit a crust weakened by the presence 
of sutures. Nonetheless, our results provide first evidence that the southern branch might extend throughout the crust with some evidence that mantle structures are also disrupted (e.g. terminations of high velocity anomalies at depths between 90 and $100 \mathrm{~km}$ ). We also see evidence in the crust indicating small-scale heterogeneity coinciding with the location of the southern and northern strands. This could be related to scattering heterogeneity related to the shear zone along the northern branch.

\section{CONCLUSION}

We have used data from a dense deployment of seismometers to analyse the scattered seismic wavefield following teleseismic $P$-wave arrivals. Extending the analysis to a tomographic inversion we detect crustal and mantle heterogeneities that can be linked to the tectonics of the region around the North Anatolian Fault Zone. The high-resolution images from the scattering tomography down to depths of $120 \mathrm{~km}$ allow unprecedented insight into the small-scale structure of a major continental strike-slip fault. We show complex structure in crust and lithospheric mantle that can be linked to modern active tectonic processes as well as the structure of the crustal terranes that form the region.

Our images show that crustal structures contrast across the southern and northern strands of the NAFZ with stark differences between the Sakarya zone, the Armutlu block and the Istanbul zone. The terminations of crustal structure are sharp within the resolution of our approach. We detect a step in Moho depth coinciding with the surface location of the northern NAFZ strand and possibly changes in Moho structure in the region of the southern strand. We detect changes of mantle structure correlated to the fault zone indicating that the NAFZ extends into the mantle to depths of at least $75 \mathrm{~km}$.

We show that scattering tomography in conjunction with dense recordings of the seismic wavefield is able to provide deeper insight into crustal and mantle structure and the fine-scale structure around fault zones. Strain localisation across the NAFZ seem to be narrow across the crust and into the mantle. This indicates that at least the upper part of the mantle lithosphere shows localized deformation which also extends throughout the crustal layer. The NAFZ likely exploits weaknesses 
due to old sutures in this region following the northwards subduction of the Tethys during the amalgamation of Anatolia.

\section{ACKNOWLEDGMENTS}

DANA (Dense Array for Northern Anatolia) is part of the FaultLab project (DANA, 2012), a collaborative effort by the University of Leeds, Boğaziçi University Kandilli Observatory and Earthquake Research Institute (BU-KOERI) and Sakarya University. Major funding was provided by the UK Natural Environment Research Council (NERC) under grant NE/I028017/1. Equipment was provided and supported by the NERC Geophysical Equipment Facility (SEIS-UK) Loan 947. This project is also supported by Boğaziçi University Scientific Research Projects (BAP) under grant 6922 and Turkish State Planning Organisation (DPT) under the TAM project, number 2007K120610. COMET is the NERC Centre for the Observation and Modelling of Earthquakes, Volcanoes and Tectonics, a partnership between UK Universities and the British Geological Survey.

\section{References}

Akbayram, K., Sorlien, C. C., \& Okay, A. I., 2016. A minimum $52 \pm 1 \mathrm{~km}$ of total offset along the northern branch of the North Anatolian Fault in northwest Turkey, Tectonophysics, $66 \mathbf{8}$ 669, $35-41$.

Aki, K. \& Richards, P. G., 2002. Quantitative Seismology, University Science Books.

Altuncu Poyraz, S., Teoman, M., Türkelli, N., Kahraman, M., Cambaz, D., Mutlu, A., Rost, S., Houseman, G., Thompson, D., Cornwell, D., Utkucu, M., \& Gülen, L., 2015. New constraints on micro-seismicity and stress state in the western part of the North Anatolian Fault Zone: Observations from a dense seismic array, Tectonophysics, 656, 190-201.

Barka, A., 1992. The north anatolian fault zone, Annales tectonicae, Vol. 6, 164-195.

Barka, A., Akyüz, H. S., Altunel, E., Sunal, G., Çakir, Z., Dikbas, A., Yerli, B., Armijo, R., Meyer, B., de Chabalier, J. B., Rockwell, T., Dolan, J. R., Hartleb, R., Dawson, T., Christofferson, S., Tucker, A., Fumal, T., Langridge, R., Stenner, H., Lettis, W., Bachhuber, J., \& Page, W., 2002. 
The surface rupture and slip distribution of the 17 August 1999 İzmit earthquake (M7.4), North Anatolian Fault, Bulletin of the Seismological Society of America, 92(1), 43-60.

Bekler, T. \& Gürbüz, C., 2008. Insight into the crustal structure of the Eastern Marmara Region, NW Turkey, Pure and Applied Geophysics, 165(2), 295-309.

Ben-Zion, Y. \& Sammis, C. G., 2003. Characterization of fault zones, Pure and Applied Geophysics, 160(3-4), 677-715.

Bostock, M. \& Rondenay, S., 1999. Migration of scattered teleseismic body waves, Geophysical Journal International, 137(3), 732-746.

Bürgmann, R. \& Dresen, G., 2008. Rheology of the Lower Crust and Upper Mantle: Evidence from Rock Mechanics, Geodesy, and Field Observations, Annual Review of Earth and Planetary Sciences, 36(1), 531-567.

Şengör, A., Tüysüz, O., İmren, C., Sakınç, M., Eyidoğan, H., Görür, N., LePichon, X., \& Rangin, C., 2005. The North Anatolian Fault: a New Look, Annual Review of Earth and Planetary Sciences, 33(1), 37-112.

DANA, 2012. Dense Array for North Anatolia (DANA), International Federation of Digital Seismograph Networks, doi: 10.7914/SN/YH_2012.

Dueker, K. G. \& Sheehan, A. F., 1997. Mantle discontinuity structure from midpoint stacks of converted P to S waves across the Yellowstone hotspot track, Journal of Geophysical Research: Solid Earth, 102(B4), 8313-8327.

Emre, Ö., Duman, T. Y., Özalp, S., Şaroğlu, F., Olgun, Ş., Elmacı, H., \& Çan, T., 2018. Active fault database of Turkey, Bulletin of Earthquake Engineering, 16(8), 3229-3275.

England, P., G., H., \& J.-M., N., 2016. Constraints from GPS measurements on the dynamics of deformation in Anatolia and the Aegean, Journal of Geophysical Research, 121, 8888-8916.

Farr, T. G., Rosen, P. A., Caro, E., Crippen, R., Duren, R., Hensley, S., Kobrick, M., Paller, M., Rodriguez, E., Roth, L., Seal, D., Shaffer, S., Shimada, J., Umland, J., Werner, M., Oskin, M., Burbank, D., \& Alsdorf, D., 2007. The Shuttle Radar Topography Mission, Reviews of Geophysics, 45(2), RG2004.

Flerit, F., Armijo, R., King, G. C., Meyer, B., \& Barka, A., 2003. Slip partitioning in the Sea of 
Marmara pull-apart determined from GPS velocity vectors, Geophysical Journal International, 154(1), 1-7.

Ford, H. A., Fischer, K. M., \& Lekic, V., 2014. Localized shear in the deep lithosphere beneath the san andreas fault system, Geology, 42(4), 295-298.

Frederiksen, A. \& Revenaugh, J., 2004. Lithospheric imaging via teleseismic scattering tomography, Geophysical Journal International, 159(3), 978-990.

Frederiksen, A. W., Thompson, D. A., Rost, S., Cornwell, D. G., Gülen, L., Houseman, G. A., Kahraman, M., Poyraz, S. A., Teoman, U. M., Türkelli, N., \& Utkucu, M., 2015. Crustal thickness variations and isostatic disequilibrium across the North Anatolian Fault, western Turkey, Geophysical Research Letters, 42(3), 751-757.

Gubbins, D., 2004. Time Series Analysis and Inverse Theory for Geophysicists, Cambridge University Press.

Gülen, L., 2002. Surface Fault Breaks, Aftershock Distribution, and Rupture Process of the 17 August 1999 İzmit, Turkey, Earthquake, Bulletin of the Seismological Society of America, 92(1), $230-244$.

Horasan, G., Gülen, L., Pinar, A., Kalafat, D., Özel, N., Kuleli, H. S., \& Isikara, A. M., 2002. Lithospheric structure of the Marmara and Aegean regions, Western Turkey, Bulletin of the Seismological Society of America, 92(1), 322-329.

Hussain, E., Hooper, A., Wright, T. J., Walters, R. J., \& Bekaert, D. P. S., 2016. Interseismic strain accumulation across the central North Anatolian Fault from iteratively unwrapped InSAR measurements, Journal of Geophysical Research: Solid Earth, 121(12), 9000-9019.

Jenkins, J., Stephenson, S. N., Martínez-Garzón, P., Bohnhoff, M., \& Nurlu, M., 2020. Crustal thickness variation across the Sea of Marmara region, NW Turkey: a reflection of modern and ancient tectonic processes, Tectonics, in press.

Ji, Y. \& Nataf, H.-C., 1998. Detection of mantle plumes in the lower mantle by diffraction tomography: theory, Earth and Planetary Science Letters, 159(3-4), 87-98.

Kahraman, M., Cornwell, D., Thompson, D., Rost, S., Houseman, G., Türkelli, N., Teoman, U., Altuncu Poyraz, S., Utkucu, M., \& Gülen, L., 2015. Crustal-scale shear zones and heteroge- 
neous structure beneath the North Anatolian Fault Zone, Turkey, revealed by a high-density seismometer array, Earth and Planetary Science Letters, 430.

Karabulut, H., Özalaybey, S., Taymaz, T., Aktar, M., Selvi, O., \& Kocaoğlu, A., 2003. A tomographic image of the shallow crustal structure in the Eastern Marmara, Geophysical Research Letters, 30(24).

Karahan, A. E., Karahan, A. E., Berckhemer, H., \& Baier, B., 2001. Crustal structure at the western end of the North Anatolian Fault Zone from deep seismic sounding, Annals of Geophysics, 44(1).

Kind, R., Eken, T., Tilmann, F., Sodoudi, F., Taymaz, T., Bulut, F., Yuan, X., Can, B., \& Schneider, F., 2015. Thickness of the lithosphere beneath Turkey and surroundings from S-receiver functions, Solid Earth, 6(3), 971-984.

Langston, C. A., 1979. Structure under Mount Rainier, Washington, inferred from teleseismic body waves, Journal of Geophysical Research, 84(B9), 4749.

Ligorría, J. P. \& Ammon, C. J., 1999. Iterative deconvolution and receiver function estimation, Bulletin of the Seismological Society of America, 89(October), 1395-1400.

Marsaglia, G. \& Bray, T., 1964. A convenient method for generating normal variable, Siam Review, 6, 260-264.

McKenzie, D., 1972. Active Tectonics of the Mediterranean Region, Geophysical Journal International, 30(2), 109-185.

Meade, B. J., Hager, B. H., McClusky, S. C., Reilinger, R. E., Ergintav, S., Lenk, O., Barka, A., \& Özener, H., 2002. Estimates of seismic potential in the Marmara Sea region from block models of secular deformation constrained by global positioning system measurements, Bulletin of the Seismological Society of America, 92(1), 208-215.

Mohsen, A., Hofstetter, R., Bock, G., Kind, R., Weber, M., Wylegalla, K., \& Rümpker, G., 2005. A receiver function study across the Dead Sea Transform, Geophysical Journal International, 160(3), 948-960.

Moore, J. D. \& Parsons, B., 2015. Scaling of viscous shear zones with depth-dependent viscosity and power-law stress-strain-rate dependence, Geophysical Journal International, 202(1), 242- 
260.

Okay, A., 1989. Tectonic Evolution of the Tethyan Region, chap. Tectonic Units and Sutures in the Pontides, Northern Turkey, pp. 109-116, Springer.

Okay, A. I., Bozkurt, E., Satır, M., Yiğitbaş, E., Crowley, Q. G., \& Shang, C. K., 2008. Defining the southern margin of Avalonia in the Pontides: Geochronological data from the Late Proterozoic and Ordovician granitoids from NW Turkey, Tectonophysics, 461(1-4), 252-264.

Paige, C. C. \& Saunders, M. A., 1982. LSQR: An algorithm for sparse linear equations and sparse least squares, ACM Trans. Math. Software, pp. 43-71.

Papaleo, E., Cornwell, D. G., \& Rawlinson, N., 2017. Seismic tomography of the North Anatolian Fault: New insights into structural heterogeneity along a continental strike-slip fault, Geophysical Research Letters, 44(5), 2186-2193.

Papaleo, E., Cornwell, D., \& Rawlinson, N., 2018. Constraints on North Anatolian Fault Zone Width in the Crust and Upper Mantle From S-Wave Teleseismic Tomography, Journal of Geophysical Research: Solid Earth, 123(4), 2908-2922.

Reilinger, R., McClusky, S., Vernant, P., Lawrence, S., Ergintav, S., Cakmak, R., Ozener, H., Kadirov, F., Guliev, I., Stepanyan, R., Nadariya, M., Hahubia, G., Mahmoud, S., Sakr, K., ArRajehi, A., Paradissis, D., Al-Aydrus, A., Prilepin, M., Guseva, T., Evren, E., Dmitrotsa, A., Filikov, S., Gomez, F., Al-Ghazzi, R., \& Karam, G., 2006. GPS constraints on continental deformation in the Africa-Arabia-Eurasia continental collision zone and implications for the dynamics of plate interactions, Journal of Geophysical Research, 111.

Revenaugh, J., 1995. Relation of the 1992 Landers, California, earthquake sequence to seismic scattering, Science, 270(5240), 1344-1347.

Robertson, A. H. \& Ustaömer, T., 2004. Tectonic evolution of the intra-pontide suture zone in the Armutlu Peninsula, NW Turkey, Tectonophysics, 381, 175 - 209.

Rondenay, S., 2009. Upper Mantle Imaging with Array Recordings of Converted and Scattered Teleseismic Waves, Surveys in Geophysics, 30(4-5), 377-405.

Ryberg, T. \& Weber, M., 2000. Receiver function arrays: a reflection seismic approach, Geophysical Journal International, 141(1), 1-11. 
Stein, R. S., Barka, A. A., \& Dieterich, J. H., 1997. Progressive failure on the North Anatolian fault since 1939 by earthquake stress triggering, Geophysical Journal International, 128, 594604.

Stern, T. A. \& McBride, J. H., 1998. Seismic exploration of continental strike-slip zones, Tectonophysics, 286(1-4), 63-78.

Tank, S. B., Honkura, Y., Ogawa, Y., Matsushima, M., Oshiman, N., Tunçer, M. K., Çelik, C., Tolak, E., \& Işıkara, A. M., 2005. Magnetotelluric imaging of the fault rupture area of the 1999 İzmit (Turkey) earthquake, Physics of the Earth and Planetary Interiors, 150(1-3), 213-225.

Taylor, G., Rost, S., \& Houseman, G., 2016. Crustal imaging across the North Anatolian Fault Zone from the autocorrelation of ambient seismic noise, Geophysical Research Letters, $\mathbf{4 3}$, $2502-2509$.

Taylor, G., Rost, S., Houseman, G., \& Hillers, G., 2019. Near-surface structure of the North Anatolian Fault zone from Rayleigh and Love wave tomography using ambeint seismic noise, Solid Earth, 10(2), 363-378.

Tibi, R., Bock, G., Xia, Y., Baumbach, M., Grosser, H., Milkereit, C., Karakisa, S., Zünbül, S., Kind, R., \& Zschau, J., 2001. Rupture processes of the 1999 August 17 İzmit and November 12 Düzce (Turkey) earthquakes, Geophysical Journal International, 144(2), F1-F7.

Van der Lee, S. \& Nolet, G., 1997. Seismic image of the subducted trailing fragments of the Farallon plate, Nature, 386(6622), 266-269.

Vanacore, E. A., Taymaz, T., \& Saygin, E., 2013. Moho structure of the Anatolian Plate from receiver function analysis, Geophysical Journal International, 193(1), 329-337.

Vauchez, A., Tommasi, A., \& Mainprice, D., 2012. Faults (shear zones) in the Earth's mantle, Tectonophysics, 558-559(null), 1-27.

Vinnik, L., 1977. Detection of waves converted from P to SV in the mantle, Physics of the Earth and Planetary interiors, 15, 39-45.

Weber, M., Abu-Ayyash, K., Abueladas, A., Agnon, A., Al-Amoush, H., Babeyko, A., Bartov, Y., Baumann, M., Ben-Avraham, Z., Bock, G., Bribach, J., El-Kelani, R., Förster, A., Förster, H.-J., Frieslander, U., Garfunkel, Z., Grunewald, S., Götze, H. J., Haak, V., Haberland, C., Hassouneh, 
M., Helwig, S., Hofstetter, A., Jäckel, K.-H., Kesten, D., Kind, R., Maercklin, N., Mechie, J., Mohsen, A., Neubauer, F. M., Oberhänsli, R., Qabbani, I., Ritter, O., Rümpker, G., Rybakov, M., Ryberg, T., Scherbaum, F., Schmidt, J., Schulze, A., Sobolev, S., Stiller, M., Thoss, H., Weckmann, U., \& Wylegalla, K., 2004. The crustal structure of the Dead Sea Transform, Geophysical Journal International, 156, 655-681.

Wu, R. \& Aki, K., 1985. Scattering Characteristics of Elastic-Waves by an Elastic Heterogeneity, Geophysics, 50(4), 582-595.

Yan, Z. \& Clayton, R. W., 2007. A notch structure on the Moho beneath the Eastern San Gabriel Mountains, Earth and Planetary Science Letters, 260(3-4), 570-581.

Yilmaz, Ö., 2001. Seismic Data Analysis, Society of Exploration Geophysicists.

Zhang, J. \& Frederiksen, A. W., 2013. 3-D crust and mantle structure in southern Ontario, Canada via receiver function imaging, Tectonophysics, 608, 700-712.

Zor, E., Sandvol, E., Gürbüz, C., Türkelli, N., Seber, D., \& Barazangi, M., 2003. The crustal structure of the East Anatolian plateau (Turkey) from receiver functions, Geophysical Research Letters, 30(24). 